\title{
Redefinir el bloque de la constitucionalidad 25 años después ${ }^{1}$
}

\author{
Itziar Gómez Fernández \\ Profesora doctora de Derecho Constitucional \\ Universidad Carlos III de Madrid
}

\begin{abstract}
Resumen: El concepto de «bloque de la constitucionalidad», inspirado en el francés «bloc de constitutionnalité», es adoptado por la doctrina española a principios de los años 80, pasando, poco tiempo después a la jurisprudencia constitucional. Desde entonces, y en 25 años de uso por el Tribunal Constitucional y la doctrina, la deriva de este concepto ha sido notable. La aproximación más simple al término, y también la más extendida, lo asocia a la idea de un conjunto de normas cuya función consiste en atribuir o modificar la atribución de las competencias de las Comunidades Autónomas, labor que la Constitución no realiza de forma directa, sino a través de algunas disposiciones de rango inferior. No obstante esta aproximación ha sido superada en la práctica y ha de reconocerse que hoy el bloque se acerca más a un concepto procesal, asociado a la función que desempeñan las normas integrantes del bloque como parámetro de la constitucionalidad del resto de disposiciones del ordenamiento jurídico.
\end{abstract}

Palabras clave: Tribunal Constitucional, Control de constitucionalidad, Conflictos de competencias, Bloque de la Constitucionalidad, «Bloc de constitutionnalité», Constitución territorial, Parámetro de control de constitucionalidad

Abstract: The term «bloque de la constitucionalidad», which refers to a group of laws that have a special constitutional nature, was inspired by the french «bloc de constitutionnalité», and was progressively adopted by the Spanish authors in the eighties, being also eventually adopted by the Constitutional Court as well. Since then, and after more than 25 years of using this term, the evolution of its legal meaning has been considerable. The most simple and widespread definition of the bloque associated the term with a set of constitutional laws that have a special authority, bestowed upon them by the Constitution, which allows them to assign or modify the level of authority of the Autonomous Communities. Since the Spanish Constitution does not directly attribute authority to the Communities, but leaves this task to the intermediary laws which form part of the bloque, their relevance would be indisputable. However, this vision of the bloque has eventually evolved into a different meaning, so that it is now more a procedural term, associated to the

\footnotetext{
${ }^{1}$ Unos apuntes iniciales que dan lugar al presente trabajo, se publicaron como último apartado del capítulo denominado «El marco normativo del sistema de organización territorial en España: el sistema de fuentes» (pp. 125-136), integrado en el libro colectivo Ordenamiento territorial en Brasil y España, bajo coordinación de la autora y de ANTONIO G. Moreira MAUÉs, y editado por Tirant Lo Blanch en 2006. En aquellas pocas páginas se apuntaban muchas de las cuestiones que ahora se desarrollan aquí.
} 
examination of the constitutionality of the rest of the laws that the Constitutional Court must undertake.

Keywords: Constitutional Court, Constitutional review, conflict of powers, «Bloque de la Constitucionalidad», «Bloc de constitutionnalité», Constitutional parameters

Sumario: 1. ¿Por qué es necesario hablar de nuevo del concepto de «bloque de la constitucionalidad»? - 2. Un retorno a los orígenes del concepto: El francés «bloc de constitutionnalité». - 3. La razón de ser del concepto: un nombre para el conjunto de normas parámetro de constitucionalidad. 4. El reconocimiento del concepto: el bloque de constitucionalidad en el ordenamiento y en la jurisprudencia constitucional española. - 5. La configuración del concepto por la doctrina: en busca del «contenido» del bloque: 5.1. La definición del bloque constitucional según la naturaleza y posición de sus normas en el ordenamiento jurídico. 5.2. La definición del bloque de constitucionalidad según su función en el ordenamiento: 5.2.1. La función de delimitación competencial. 5.2.2. La función procesal de parámetro. - 6. Las normas que integran un bloque de la constitucionalidad caracterizado por la consideración de su función procesal de parámetro.-7. De un bloque de reparto competencial a un bloque con función procesal de parámetro de constitucionalidad.

\section{1. ¿Por qué es necesario hablar de nuevo del concepto de «bloque de la constitucionalidad»?}

El concepto de bloque de la constitucionalidad está presente en la doctrina jurídica española desde que Tomás Ramón Fernández lo utilizara por primera vez en lengua castellana en el año 1981, trasladándolo desde la doctrina francesa, en un trabajo denominado «Las leyes orgánicas y el bloque de la constitucionalidad $»^{2}$. En los 25 años transcurridos desde entonces, el contenido dado a esta expresión por la doctrina ${ }^{3}$ y por la jurisprudencia constitucional, que acabó asumiéndolo como terminología de uso corriente en el ejercicio su actividad, ha ido variando, aunque no se haya reconocido siempre de forma expresa esta mutación,

2 En esta monografía publicada por Civitas en 1981, y cuyo título completo es Las leyes orgánicas y el bloque de la constitucionalidad: en torno al artículo 28 de la Ley Orgánica del Tribunal Constitucional, el autor utiliza el concepto de «bloque de la constitucionalidad» vinculándolo a la posición y función de las leyes orgánicas en el ordenamiento jurídico.

${ }^{3}$ Realiza una aproximación al concepto Lorenzo RodrígueZ-Armas, M.: «Reflexiones en torno al concepto del bloque de la constitucionalidad», en Anuario jurídico y económico escurialense, núm. 33, 2000, pp. 193-210. 
y aunque apenas se haya recogido en el ámbito normativo, ni constitucional ni infraconstitucional ${ }^{4}$, el citado término de bloque de constitucionalidad.

El objeto de las páginas que siguen es recorrer la evolución del concepto, tratando de conformar el contenido actual del mismo y poniéndolo en paralelo al muy cercano de parámetro de constitucionalidad que, aunque habitualmente es utilizado como sinónimo absoluto del bloque, en realidad se comporta con él como un todo en relación con una de sus partes.

A pesar de lo que pudiera parecer, al aproximarse a esta cuestión no se acomete un problema meramente conceptual. La importancia del afán de precisión que guía un análisis sobre el contenido y definición del bloque de constitucionalidad se centra en la importancia que el concepto tiene para considerar la estructura de nuestro sistema normativo, y ello porque se puede llegar a establecer que las normas del ordenamiento jurídico puede ser clasificadas en dos grupos distinguiendo entre las que se integran en el bloque y las restantes ${ }^{5}$. Las primeras se caracterizarían por describir un particular haz de relaciones con el resto de normas del ordenamiento, en la medida en que las disposiciones del bloque contienen pautas de validez de las que, siendo parte del ordenamiento interno, no se integran en tal bloque. De este modo las disposiciones en él contenidas se constituirían en parámetro directo de la constitucionalidad del resto de disposiciones del ordenamiento. Así pues, una buena definición del bloque de constitucionalidad permitirá comprender de modo más completo el ordenamiento español, percibiendo su complejidad y acercándose con más precisión a los principios de resolución de antinomias internorma-

4 En cualquier caso el reconocimiento normativo se da en disposiciones no vinculantes - como las exposiciones de motivos - o en normas de contenido y alcance limitados. Así el Preámbulo de la Ley 2/1986, de 13 de marzo, de Cuerpos y Fuerzas de Seguridad del Estado, proclama la inclusión de la misma en el bloque de constitucionalidad acudiendo para ello a la jurisprudencia del Tribunal Constitucional sobre la materia. Existen también algunas otras referencias colaterales al concepto en las exposiciones de motivos de otras normas de rango infralegal, como la Orden de 3 de abril de 1996 para el establecimiento del III Plan de acciones prioritarias contra incendios forestales, o en circulares internas del Ministerio Fiscal, como la Circular 2/1999, de 30 de diciembre, sobre intervención del Fiscal en las cuestiones de inconstitucionalidad en sede judicial. La única alusión expresa al bloque contenida en el articulado de una disposición normativa es la que se realiza en el apartado decimoprimero de la Resolución de 10 de marzo de 1995, de la Secretaría de Estado para las administraciones territoriales, por la que se dispone la publicación del acuerdo de la conferencia para asuntos relacionados con las comunidades europeas sobre la participación interna de las Comunidades Autónomas en los asuntos comunitarios europeos a través de las conferencias sectoriales (BOE de 22 de marzo de 1995).

5 Así lo hace, por ejemplo, Orozco MuÑoz, M.: El régimen especial de Canarias. Su conformación por el Bloque de Constitucionalidad. Monografías Jurídicas. Marcial Pons. Madrid, 1997. 
tivas o interordinamentales ${ }^{6}$ que se formulan en el propio ordenamiento para garantizarse una estructura previsible y objetiva del mismo.

Junto a ello, profundizar en el concepto de bloque de constitucionalidad es una forma de aproximarse a la cuestión de la interpretación de la Constitución que realizan los jueces - entre los que destacan los miembros del Tribunal Constitucional - y que se caracteriza por la absoluta libertad de construcciones existente al respecto. Si bien en ocasiones el propio texto constitucional, o las normas con rango legal que articulan el modelo de control de constitucionalidad - en el caso español la ley orgánica 2/1979, del Tribunal Constitucional - , proporcionan pautas que orientan o constriñen la actividad hermenéutica de los jueces constitucionales $^{7}$, la regla general es que son la doctrina jurídica, y la propia jurisprudencia constitucional quienes se encargan de formular los conceptos que les serán útiles en aras a realizar una mejor labor interpretativa. Y en esta línea de creación conceptual, una de las nociones más conocidas es la de bloque de la constitucionalidad, que se ha extendido a otras jurisdicciones constitucionales - notablemente de Iberoamérica ${ }^{8}$ - y ha adquirido, no obstante los problemas vinculados a su alcance y contenido, una cierta importancia y un reconocimiento por buena parte de la doctrina constitucional.

${ }^{6}$ Sobre el contenido de estos dos tipos de conflictos y las reglas de solución de antinomias véase GómEZ FERnÁNDEZ, I.: Conflicto y Cooperación entre la Constitución y el Derecho Internacional, Tirant Lo Blanch, Valencia, 2005, pp. 39 y ss.

7 Entre estas pautas cabe citar las contenidas en los artículos 28 y 73 de la Ley Orgánica del Tribunal Constitucional, sobre las cuales se reflexionará con profusión en este texto y, especialmente, la que se describe en el art. 10.2 CE, que establece que «las normas relativas a los derechos fundamentales y a las libertades que la Constitución reconoce, se interpretarán de conformidad con la Declaración Universal de Derechos Humanos y los tratados y acuerdos internacionales sobre las mismas materias ratificados por España», de manera que dichos tratados internacionales constituyen parámetro constitucionalmente establecido y necesario para proceder a la interpretación de los derechos fundamentales. El libro más completo escrito en España hasta la fecha sobre el alcance y contenido del art. 10.2 CE, es la monografía de SAIZ ARNAIZ, A.: La apertura constitucional al Derecho Internacional y Europeo de los Derechos Humanos: el artículo 10.2 de la Constitución Española. Consejo General del Poder Judicial. Madrid, 1999.

${ }^{8}$ Un ejemplo notable viene constituido por la jurisprudencia y doctrina colombianas en relación con el bloque de constitucionalidad. Dos de las sentencias constitucionales destacables al efecto, son la Sentencia T-409 de 1992, por ser la primera en utilizar normas externas a la Constitución escrita como parámetro del control de constitucionalidad, y la Sentencia C-225 de 1995, primera que sistematiza la idea de bloque. Resulta de interés consultar también, en la medida en que resume la jurisprudencia colombiana al afecto, la Sentencia C-067/03. En relación con toda esta cuestión véase el trabajo de RAMELLI, A.: «Sistema de fuentes de derecho internacional público y "bloque de constitucionalidad" en Colombia», en Cuestiones constitucionales: revista mexicana de derecho constitucional, núm. 11, 2004. 


\section{Un retorno a los orígenes del concepto: El francés «bloc de constitutionnalité»}

El concepto de bloque de la constitucionalidad de traslada por la doctrina española desde la francesa, dos de cuyos constitucionalistas contemporáneos más conocidos, Löic Philip y Louis Favoreu, acuñan el término adaptando el concepto administrativo de «bloque de legalidad».

Este concepto de bloc de constitutionnalité, cuya creación fue puramente doctrinal ya que el Conseil Constitutionnel no empleó al inicio esta expresión en sus decisiones, trata de englobar en una categoría única todas las normas, principios y reglas de valor constitucional ${ }^{9}$ que el Conseil utiliza en el momento de realizar un control preventivo sobre la validez o ajuste constitucional de las leyes orgánicas, las leyes ordinarias y los reglamentos parlamentarios ${ }^{10}$. La primera vez que el Conseil utiliza normas no incluidas en el texto constitucional para formular un juicio de constitucionalidad es en la Decisión núm. 66-28 de 8 de julio de 1966, no obstante se cita como hito con mayor frecuencia, dada su importancia, la Decisión núm. 71-44 de 6 de julio de $1971^{11}$, en relación con la «Loi complétant les dispositions des articles 5 et 7 de la loi du 1er juillet 1901 relative au contrat d'association» [Journal Oficiel de 18 de julio de 1971, p. 7114], decisión a la que se une, por su relevancia material y en relación con la configuración del bloque, la Decisión

9 Algún otro autor como FrançOIS LuCHAIRE - Le Conseil Constitutionnel. Economica, Paris, 1980, pp. 131 y ss. - , prefirió caracterizar este conjunto de normas como normas supra-legales, argumentando esta caracterización en la ausencia de naturaleza o valor constitucional de algunas de ellas.

10 Se puede encontrar una completa referencia al concepto y contenido del bloc de constitutionnalité en FAVOREU, L.: «El bloque de la constitucionalidad. Ponencia francesa», en FAVOREU, L. y Rubio LloRente, F.: El bloque de la constitucionalidad (Simposium franco-español). Universidad de Sevilla, Editorial Civitas, Madrid, 1991, pp. 19 y ss. [publicado también en Revista del Centro de Estudios Constitucionales, núm. 5, 1990, pp. 4568]; Requejo Rodríguez, P.: Bloque constitucional y bloque de la constitucionalidad. Universidad de Oviedo, Servicio de publicaciones. Oviedo, 1997, p. 25; RuBio LlORENTE. F: «El bloque de Constitucionalidad», en VV.AA.: Estudios sobre la Constitución Española. Homenaje al profesor Eduardo García de Enterría. Vol. I. Civitas, Madrid, 1991, p. 8 [también publicado en $R E D C$. N. ${ }^{\circ}$ 27, año 9, septiembre-diciembre, 1989, pp. 12 y ss. y en VV.AA.: La forma del poder. Estudios sobre la Constitución. CEPC. Madrid, 1997, pp. 63 y ss.]

11 Se analiza el contenido y alcance de la decisión núm. 71-44 en BEARDSLEY J.E: «The Constitutional council and Constitutional liberties in France», en American journal of comparative law, 1972, p. 431-452; HAIMBOWGH, G.: « Was it France's Marbury v. Madison?», en Ohio State Law Journal, 1974, vol. 35, p. 910; Hamon, L.: Contrôle de constitutionnalité et protection des droits individuels, Dalloz, 1974, chron., pp. 83-90 ; Robert, J.: «Propos sur le sauvetage d'une liberté», en Revue de Droit Public, 1971, pp. 1171 y ss. 
núm. 74-54 de 15 de enero de 1975, sobre la «Loi relative à l'interruption volontaire de la grossesse» ${ }^{12}$.

Por su parte, la primera vez que el Conseil emplea este término es mucho después de que lo haga el Tribunal Constitucional español, en una decisión de 1998, la núm. 98-399 DC de 5 de mayo de 1998, sobre la ley relativa a la entrada, permanencia y derecho de asilo de los extranjeros. No obstante, no se encuentran caracteres o definiciones del bloque o de las normas que lo integran más que en la Decisión núm. 98-403 DC de 29 de julio de 1998, donde se dice que las leyes integrantes del bloque tienen el mismo valor que la propia Constitución y en la Decisión núm. 2001-450 DC, de 11 de julio de 2001, donde se reconoce que el concepto ha sido creado y configurado por la jurisprudencial del Conseil constitutionnel.

Ahora bien, ¿supone la traslación de este término a la esfera del ordenamiento español el simultáneo traspaso de su contenido material o su significado? La respuesta ha de ser negativa. Y es que se produce una disociación entre traspaso de denominación y transposición del contenido material que se le asocia, disociación que se acentúa si se reconoce que el concepto francés, desde su origen en los años setenta, y el español, desde su incorporación doctrinal a principios de los ochenta, han ido evolucionando describiendo líneas esencialmente divergentes.

Por su parte la línea francesa ha supuesto el paso de la utilización de parámetros de constitucionalidad centrados en principios fundamentales que daban un amplio margen de maniobra al Conseil, al uso de un parámetro más preciso ${ }^{13}$. Esto ha supuesto la progresiva concreción del bloc de constitucionnalité y la cerrazón paulatina de sus límites. Actualmente cuando el Conseil actúa en el marco del control de constitucionalidad que opera en función del art. 61 de la Constitución francesa, opta por apoyarse en las disposiciones contenidas en los textos constitucionales, habiéndose reducido en los últimos veinte años el conjunto de las categorías de normas de referencia, de manera que podría decirse que el bloc de constitutionnalité, se compone exclusivamente de textos de nivel constitucional ${ }^{14}$ entre los que cabe citar la Constitución de 1958, la Declaración de Derechos del hombre y del ciudadano de 1789, el Preámbulo de la Constitución de 1946,

12 En relación con esta sentencia y el mantenimiento de la jurisprudencia de ella derivada, resulta interesante el comentario de GenEvoIs, B.: «Faut-il maintenir la jurisprudence issue de la décision 74-54 DC du 15 janvier 1975?», en Les Cahiers du Conseil constitutionnel, 1999 (7), p. 101.

13 Favoreu, L.: «El bloque de la constitucionalidad. Ponencia francesa». Op. cit., p. 19.

${ }^{14}$ Realizan un profundo análisis de los textos normativos incluidos en el bloc de constitutionnalité LuChaIRe, F.: Le Conseil Constitutionnel. Op. cit., pp. 131 y ss.; y PARDO FALCón, J.: El Consejo Constitucional Francés. CEPC. Madrid, 1990, pp. 116 y ss. 
y las leyes de la República en la medida en que sean portadoras de ciertos «principios fundamentales» ${ }^{15}$, que se erigen en parámetro directo. Según esto, quedarían excluidos del bloque, entre otros elementos normativos, los reglamentos de las Asambleas Parlamentarias ${ }^{16}$, así como toda fuente de derecho internacional o Derecho Comunitario.

Mientras tanto, en la línea de evolución jurisprudencial española, la indefinición ha sido progresivamente mayor y probablemente interesada por el propio Tribunal Constitucional, lo cual ha supuesto una ampliación - a la que se hará referencia más adelante- del contenido del bloque de la constitucionalidad que no ha visto aún su final.

Así pues, hoy por hoy, bloc de constitutionnalité y bloque de constitucionalidad han dejado de ser términos de idénticos contenidos, términos gemelos podría decirse, para convertirse en primos lejanos que, sin dejar de estar conectados, no se definen ya del mismo modo ${ }^{17}$.

Seguramente la idea esencial que vertebra el concepto de bloc de constitutionnalité que es la idea de unidad, de conglomerado de normas complementarias de la Constitución, esté también presente en la noción de bloque. En realidad en España la configuración del «nuevo ordenamiento jurídico» de la democracia, que se da en los primeros años de la década de los ochenta, buscaba un concepto que expresara tal comple-

15 En la demanda de inconstitucionalidad presentada por un grupo de diputados en relación con la Loi relative à l'entrée et au séjour des étrangers en France et au droit d'asile dite «RESEDA», - resuelta por Decisión núm. 98-399 DC de 5 de mayo de 1998 - los recurrentes establecen, de acuerdo con la jurisprudencia de la Corte, que esos principios son aquellos que fueron elaborados por el legislador y que habían recibido aplicación con una constancia suficiente antes de la Constitución de 27 de octubre de 1946.

16 Danzeau, Ch: Existe-t-il un bloc de constitutionnalité? LGDJ/Montchrestien. París, 1997, pp. 105 y ss. En relación con la exclusión de los Reglamentos de las Asambleas Parlamentarias del bloque de constitucionalidad, véanse las decisiones núm. 80-267 DC de 19 y 20 de enero de 1981, núm.93-334 DC de 20 de enero de 1994 o la núm.99-419 DC de 9 de noviembre de 1999. Por lo que hace a la exclusión de los tratados y otras fuentes internacionales del bloque, véase por todas la decisión núm.74-54 DC de 15 de enero de 1975.

17 Esta diferencia no sólo se constata entre el contenido dado al término francés y al término en España, sino que se evidencia también si se comparan los distintos contenidos que se dan al bloque en los países de América Latina. En los países de Iberoamérica suele utilizarse la idea de bloque asociándola a la posición de los tratados internacionales de Derechos Humanos en relación con las Constituciones nacionales. En buena parte de los Estados del subcontinente americano se constata cómo sus constituciones recogen cláusulas de apertura al derecho internacional de los Derechos Humanos, admitiendo la posibilidad de que las declaraciones de derechos que lo conforman sean fuente directa de derechos subjetivos a nivel nacional, o fuente de interpretación de las disposiciones constitucionales, o parámetro de referencia del control de constitucionalidad de las normas internas con rango de ley. Así pues en este ámbito el bloque adquiere un contenido diferente del que tiene en España y en Francia, donde, como se verá, se excluye expresamente la posibilidad de considerar los tratados internacionales como parte integrante del bloque. 
mentariedad ${ }^{18}$, y quizá por eso se toma no sólo la clave del instrumento jurídico, sino su propio nomen. Pero pronto se percibió que el contenido de ese título jurídico galo era superado por unas exigencias mayores procedentes de un ordenamiento constitucional en construcción, y surgido de una Constitución abierta e indefinida en muchos ámbitos, especialmente en el referido a la organización territorial del poder. A partir de ahí comienza una evolución del concepto de bloque de constitucionalidad que cada vez lo alejó más de la noción que lo inspiró y que está arribando a una indefinición notable, de forma tal que ni siquiera está perfectamente determinado el elenco de las fuentes que lo componen, ni se pueden determinar éstas sobre la base de un común denominador, como su función o su naturaleza constitucional, y ni siquiera se puede hacer un listado cerrado a priori de las normas que integran el bloque, porque este listado va aumentando a medida que avanza la tarea hermenéutica del Tribunal Constitucional.

A pesar de ello la constatación de semejantes circunstancias, y como dijera en su día Francisco Rubio Llorente, «se opera con la expresión como si ésta denotara una categoría normativa perfectamente definida o al menos un conjunto de normas perfectamente identificables» ${ }^{19}$, lo cual no parece que sea en absoluto cierto. Sin perjuicio de esta duda razonable, conviene tratar de definir los conceptos que se utilizan en el terreno de lo jurídico, puesto que no fijar el concepto de bloque puede llegar a inutilizar el término debido a que dicha imprecisión llevaría aparejado un cierto grado de inseguridad jurídica, y la misma es un claro obstáculo para la realización del principio constitucionalmente reconocido de justicia, al que parece servir, entre otros, la utilización del término bloque de constitucionalidad, en la medida en que el mismo se emplea con la finalidad de alcanzar un mayor grado de precisión en la tarea de depuración del ordenamiento jurídico por parte del Tribunal Constitucional.

18 Según Miguel Ángel Aparicio esta complementariedad tenía que ver con la relación entre la Constitución y las leyes orgánicas - véase «Sobre la configuración del modelo territorial del Estado y el bloque de la constitucionalidad», en VV.AA.: Informe Pi i Sunyer sobre Comunidades Autónomas 1995-1996. Fundació Carles Pi i Sunyer d'Estudis Autonòmics i Locals. Barcelona, 1996, p. 969, también publicado en García Herrera, M.A. (Coord.): El constitucionalismo en la crisis del estado social, 1997, pp. 533-553-. No obstante, y aunque efectivamente este es el alcance originario que se le da a la noción de bloque de constitucionalidad por TOMÁs RAMÓN FERNÁNDEZ en la obra que incorpora al ordenamiento español este concepto, - Las leyes orgánicas y el bloque de la constitucionalidad: en torno al artículo 28 de la Ley Orgánica del Tribunal Constitucional, op. cit. - esta conexión se rompe pronto para pasar a considerarse el bloque, como se verá, un conjunto de normas, no necesariamente leyes orgánicas, que completan los aspectos constitucionales de la distribución territorial del poder.

19 Rubio Llorente. F: «El bloque de Constitucionalidad», op. cit., p. 3. 


\section{La razón de ser del concepto: un nombre para el conjunto de normas parámetro de constitucionalidad}

El concepto de bloque de constitucionalidad se ha utilizado - en la doctrina y la jurisprudencia españolas, del mismo modo que en la doctrina gala - , para denominar de forma conjunta a las normas que actúan como parámetro de constitucionalidad y que son utilizadas por el juez constitucional en su labor de control de ajuste entre las disposiciones infraconstitucionales y el texto de la Constitución. Del diseño de tal parámetro va a depender en buena medida tanto el alcance de los pronunciamientos del Tribunal como las perspectivas de los sujetos legitimados para incoar el control de constitucionalidad que, a medida que se amplíe dicho parámetro, contarán con un mayor número de normas con las que confrontar la disposición o acto que sea objeto de su impugnación.

El «parámetro de constitucionalidad» ${ }^{20}$, desde una perspectiva esencialmente teórica, viene constituido por aquellas disposiciones legales que el juez utiliza como referente a la hora de someter a control de ajuste constitucional las normas con rango de ley, las disposiciones, resoluciones o actos de los poderes públicos centrales o autonómicos, y los actos ejecutados por los agentes del poder público. Esto significa que éste es el instrumento del que se sirve de forma esencial el Tribunal Constitucional, sobre las premisas planteadas en la Constitución, para formular las condiciones de validez del conjunto de disposiciones y actos singulares que integran el sistema jurídico.

Por lo general, la norma que establece los criterios de validez del resto de las disposiciones y actos jurídicos es la Constitución en sentido for$\mathrm{mal}^{21}$, pero nuestro ordenamiento va más allá, extendiendo las normas

${ }^{20}$ Además de definir este concepto de forma autónoma, como se hace en estas líneas también puede definirse por oposición al concepto «parámetro de interpretación», que estaría constituido por los criterios de todo tipo que el Tribunal Constiutcional utilizará para comprender mejor el alcance de las normas que integran el parámetro de constitucionalidad. Es decir el parámetro de interpretación se refiere a las disposiciones auxiliares utilizadas por el Tribunal en su labor hermeneútica, para determinar el significado de la Constitución y el resto de normas integradas en el bloque de constitucionalidad. Es cierto que, aunque la diferencia teórica entre parámetro de control de constitucionalidad y parámetro de interpretación puede plantearse en estos términos, en la práctica es difícil trazar la línea fronteriza que separa uno y otro. Sobre todas estas cuestiones, y en especial sobre su relación con la utilización del Derecho Internacional por parte del Tribunal Constitucional como parámetro (de control o de interpretación) en el desarrollo de su labor jurisprudencial, véase mi trabajo Conflicto y cooperación entre la Constitución y el Derecho Internacional (op. cit.), pp. 355 y ss.

${ }^{21}$ Acerca de los conceptos de Constitución formal y Constitución material, vide JIMÉNEZ CAMPO, J.: «Contra la Constitución material». En VV.AA.: Estudios de Derecho Público (Homenaje a J. J. Ruiz Rico). Vol. I. Tecnos. Madrid, 1997, pp. 32 y ss. Sobre este tema 
susceptibles de contener criterios de validez fuera de los límites del texto constitucional de 1978 y, por tanto, ampliando el contenido del concepto de parámetro de control de constitucionalidad y permitiendo desdoblar, de nuevo y desde una consideración puramente teórica, el concepto en dos: por un lado el parámetro directo de control, y por otro el parámetro indirecto de control.

Integrarán el contenido del primero, las fuentes a las que el Tribunal Constitucional haga referencia directa, tanto en su razonamiento, como en el fundamento del fallo declarativo de constitucionalidad o de inconstitucionalidad, para determinar el ajuste de la norma objeto de control al sistema constitucional que conformarán tanto la Norma de normas, como las fuentes parámetro que completan los contenidos de la Constitución.

El segundo, el parámetro de control indirecto, se basa en la concepción italiana de la «normativa interpuesta», que se refiere a determinadas normas de carácter no constitucional que se comportan, de acuerdo con lo que establecen disposiciones formalmente constitucionales, como condiciones de validez de ciertas normas con rango de ley. A pesar de que un buen número de autores de la doctrina española se refieren a este concepto ${ }^{22}$, el Tribunal Constitucional no lo incorpora ni expresa ni tácitamente a su jurisprudencia, antes bien se opone a su utilización, y en la medida en que el fundamento de su fallo sea una disposición constitucional, con la que concuerde o a la que se oponga la disposición objeto del control de constitucionalidad, el Tribunal Constitucional entiende que las fuentes interpuestas en que apoya su razonamiento, pero que le conducen a la alusión expresa y directa de un precepto constitucional, no son más que pautas interpretativas, con lo cual entrarían en el ámbito del parámetro de interpretación ${ }^{23}$. Así pues, por lo que hace al ordenamiento español y a la interpretación que de él hace el Tribunal Constitucional, cuando hablamos de parámetro de constitucionalidad nos estaremos refiriendo al parámetro directo de constitucionalidad.

Un parámetro de constitucionalidad como el que se expone aquí, que exceda el propio texto constitucional, se entiende en aquellos sistemas en los cuales la Constitución es una norma abierta, en el sentido de que no agota la regulación de todos los aspectos que son esenciales a la configuración defi-

también hace alguna consideración LÓPEZ AGUILAR, J. F.: Lo constitucional en el Derecho: sobre la idea e ideas de Constitución y Orden Jurídico. CEPC. Madrid, 1998, p. 46.

22 Defiende especialmente la utilización de este concepto ReQueJo PAGÉs, J.L.: «Constitución y remisión normativa. Perspectiva estática y dinámica en la identificación de las normas constitucionales», $R E D C$, núm. 39, septiembre - diciembre. 1993, pp. 115 y ss, aquí especialmente p. 119.

23 Véase Gómez Fernández, I.: Conflicto y cooperación entre la Constitución y el Derecho Internacional, op. cit., pp. 358-359. 
nitoria del sistema jurídico que diseña ${ }^{24}$. Las Constituciones suelen remitirse con frecuencia a otras normas para proceder a la configuración definitiva o completa de sus contenidos y en el ordenamiento jurídico español estas remisiones, que pueden ser expresas o tácitas, se refieren principalmente a la distribución de competencias entre distintos entes, y esencialmente a la distribución de poderes entre el Estado y las Comunidades Autónomas. Podría decirse, pues, que en España el concepto de parámetro amplio de constitucionalidad surge esencialmente porque la Constitución no realiza un reparto o atribución de materias o competencias a las distintas Comunidades Autónomas, sino que son normas infraconstitucionales como los Estatutos de Autonomía (art. $147 \mathrm{CE}$ ) y las leyes a que se refiere el art. $150 \mathrm{CE}$-leyes marco, leyes de transferencia y leyes de armonización ${ }^{25}$ - los que hacen surgir al mundo jurídico y político las Comunidades Autónomas y asumen, haciendo uso del principio dispositivo, las competencias que llenarán de contenido la autonomía de nacionalidades y regiones ${ }^{26}$.

Pero más allá de la definición de la estructura territorial del Estado, resulta preciso convenir que el resto de la Constitución no se halla absolutamente cerrada y definida, sino que es una norma abierta en aspectos que no se vinculan estrictamente al reparto competencial entre Estado y Comunidades Autónomas. Un ejemplo claro es la previsión de la integración supranacional del Estado español en algún tipo de organización internacional a la que pueda cederse el ejercicio de competencias derivadas de la Constitución. Esta previsión del artículo 93 CE no cierra el diseño constitucional de la que en 1978 era eventual y hoy es real, integración supranacional, y que sólo se hará efectivo tras la ratificacion de los tratados de adhesión a las Comunidades Europeas ${ }^{27}$.

Como observación final cabe decir que la idea amplia de parámetro de referencia, que sobrepasa los dictados literales del texto constitucional superándolos, esconde una idea amplia de supremacía constitucional. Sólo si

${ }^{24}$ Requejo Pagés, J.L.: «Constitución y remisión normativa. Perspectiva estática y dinámica en la identificación de las normas constitucionales», op. cit., p. 119.

25 Sobre el contenido material y los requisitos formales de estas tres categorías normativas puede consultarse GómEZ FERNÁNDEZ, I.: «El marco normativo del sistema de organización territorial en España: el sistema de fuentes», op. cit., pp. 23 y ss.

${ }^{26}$ En relación con esta cuestión en concreto, véase la primera parte de la monografía de GómEZ FERNÁNDEZ, I.: Conflicto y Cooperación entre la Constitución y el Derecho Internacional, op. cit., especialmente pp. 101 y ss.

27 Sobre el alcance y significado actuales del art. 93 CE, tras la Declaración 1/2004 del Tribunal Constitucional, que modula el contenido del precepto modificando la jurisprudencia previa a él referida, véase GómEZ FERNÁNDEZ, I.: «La Constitución Española "frente” al Tratado por el que se establece una Constitución para Europa: entre la necesidad y la conveniencia de una reforma constitucional», en Revista española de Derecho Europeo, núm. 14, abril- junio, 2005, pp. 297-327, y sobre esta cuestión especialmente páginas 318-322. 
se entiende que las normas que componen el bloque acatan esa supremacía, es decir, respetan unos principios constitucionales básicos de los que cabe predicar esa supremacía y que conforman el núcleo material básico de la Constitución, podrán a su vez ser utilizados como referente. Estas normas formalmente no constitucionales, que vienen a completar dictados de la carta magna y que, por esa razón, es preciso utilizar como referente de control, no podrán someterse más que a esas condiciones básicas de ejercicio de la soberanía, porque más allá de eso son ellas mismas las que completan los dictados constitucionales y terminan de dar forma a ciertas previsiones constitucionales amplias, abstractas o con cierto grado de indefinición.

\section{El reconocimiento del concepto: el bloque de constitucionalidad en el ordenamiento y en la jurisprudencia constitucional española}

En la Constitución española no se hace referencia alguna al parámetro de control que deberá usar el Tribunal Constitucional para juzgar la constitucionalidad de las normas, aunque se deduce que será la propia norma fundamental, en virtud de los principios de supremacía y aplicabilidad directa de la misma (deducibles de los arts. 1.2 9.1, 95, 161, 163, 167, 168 y Disposición Derogatoria de la CE) ${ }^{28}$. Por ello es necesario acudir a la Ley Orgánica del tribunal Constitucional (LOTC) para encontrar la primera referencia normativa al parámetro de control, y por tanto al bloque de la constitucionalidad, aunque la ley orgánica no utilice este término. Esas referencias normativas están presentes en los artículos 28 y 73 LOTC 29.

El art. 28.1 LOTC establece que el Tribunal Constitucional tomará en consideración para llevar a cabo su función de control de constitucionali-

${ }^{28}$ Según la doctrina mayoritaria, la supremacía de la Constitución española se deduce principalmente del art. 9.1 CE, no obstante algunos autores aseguran que a este precepto ha de unirse, para deducir esa supremacía, lo contenido en el art. 95 CE respecto del Derecho internacional. En este sentido Ferreres Comella, V. y Saiz Arnaiz, A.: «¿Realmente hay que reformar la Constitución española para adecuarla a la cláusula de primacía de la Constitución europea?», en Actualidad Jurídica Aranzadi, año XIV, núm. 645, pp. 1-6. Asimismo, reflexiona sobre el nuevo alcance del art. 9.1 CE, tras las innovaciones jurisprudenciales introducidas al respecto por la Declaración 1/2004 del Tribunal Constitucional, GóMEZ FERNÁNDEZ, I.: «La Constitución Española "frente" al Tratado por el que se establece una Constitución para Europa: entre la necesidad y la conveniencia de una reforma constitucional», op. cit., pp. 306 y ss.

29 Esta Ley Orgánica es modificada por las Leyes, también orgánicas, 8/1984, 4/1985, $6 / 1988,7 / 1999$ y $1 / 2000$. Actualmente se haya en tramitación parlamentaria una reforma global de la ley. Puede consultarse el texto del Proyecto de Ley orgánica de reforma en el Boletín Oficial de las Cortes Generales Núm. 60-1 (Congreso de los Diputados, VIII legislatura), de 25 de noviembre de 2005. 
dad de normas con rango de ley tanto los preceptos constitucionales como las leyes que, de acuerdo con los dictados de la norma fundamental, se hubieran elaborado para delimitar, regular o armonizar las competencias entre el Estado y las Comunidades Autónomas. Este precepto vincula el concepto de parámetro sólo a los procesos de control de constitucionalidad de normas con fuerza de ley del Estado y de las Comunidades Autónomas. Tal vinculación deriva de la ubicación de este artículo situado dentro del capítulo I (Disposiciones generales), del Título II (De los procedimientos de declaración de inconstitucionalidad) de la LOTC, pero si se acude a lo previsto en los arts. 59.1 y 73 LOTC (vide infra) no parece que exista inconveniente para considerar aplicable un concepto amplio de parámetro a los conflictos constitucionales: conflictos de competencias, de atribuciones y en defensa de la autonomía local ${ }^{30}$. De hecho, en la práctica, el Tribunal Constitucional utiliza esencialmente el concepto del bloque que se deriva del art. 28.1 LOTC cuando resuelve conflictos de competencias positivos (SSTC 88/89, 148/92), o negativos (SSTC 156/90 y 37/92, AATC 142/1989, 322/1989 y 357/1990).

No obstante, el artículo 28.1 LOTC, es el precepto que habitualmente se toma como referente doctrinal al aludir al concepto de bloque de la constitucionalidad. Aunque el propio precepto no habla de bloque, ni de parámetro, es evidente que lo que hace es establecer un grupo de normas que el Tribunal Constitucional tendrá la posibilidad de utilizar para apreciar la conformidad o disconformidad constitucional de normas con valor de ley tanto del Estado como de las Comunidades Autónomas.

En el apartado 2 de este mismo artículo, la LOTC parece ofrecer un segundo parámetro al afirmar que «el Tribunal podrá declarar inconstitucionales por infracción del art. 81 de la Constitución los preceptos de un decreto-ley, decreto legislativo, ley que no haya sido aprobada con el carácter de orgánica o norma legislativa de una Comunidad Autónoma en el caso de que dichas disposiciones hubieran regulado materias reservadas a ley orgánica o impliquen modificación o derogación de una ley aprobada con tal carácter, cualquiera que sea su contenido». De la dicción literal de este precepto ha querido deducirse en algún momento que las leyes orgánicas se convertían en parámetro de validez del resto de normas del ordenamiento que con ellas entrasen en contradicción, y que, por tanto, pasaban a integrarse todas ellas en el bloque de constitucionalidad. Pero la doctrina mayoritaria, encabezada por Tomás Ramón Fernández, sostiene la tesis de que el

${ }^{30}$ En cambio no puede hacerse la misma extensión vinculando este concepto a los procesos de amparo, puesto que en este caso la propia Constitución (art. 53. 2 CE) y la Ley Orgánica del Tribunal Constitucional (art. 41), limitan estrictamente el parámetro de control a los artículos 14 a 29 y 30.2 de la Constitución. 
art. 28.2 LOTC simplemente establece la relación entre leyes orgánicas y leyes ordinarias, siendo el parámetro directo de control de las segundas el artículo $81 \mathrm{CE}$. Dicho de otro modo que los preceptos de un decreto-ley, un decreto legislativo, una ley estatal ordinaria o la norma legislativa de una Comunidad Autónoma pueden ser declarados inconstitucionales por invadir materias reguladas mediante ley orgánica, pero no serán inconstitucionales por la insuficiencia de rango, o por contradicción con una ley orgánica, sino por la infracción del artículo 81 de la Constitución española ${ }^{31}$.

Por su parte, como se ha dicho, el art. 73.1 LOTC L $^{32}$ también hace referencia a un parámetro de control que va más allá de los dictados de la Constitución, al establecer que «en el caso en que alguno de los órganos constitucionales a los que se refiere el artículo 59.1.c) de esta Ley, por acuerdo de sus respectivos Plenos, estime que otro de dichos órganos adopta decisiones asumiendo atribuciones que la Constitución o las Leyes orgánicas confieren al primero, éste se lo hará saber así dentro del mes siguiente a la fecha en que llegue a su conocimiento la decisión de la que se infiera la indebida asunción de atribuciones y solicitará de él que la revoque». Si en el art. 28 LOTC se habla de leyes que completan a la Constitución en lo que hace al reparto territorial del poder, en el art. 73.1 LOTC se alude a las leyes orgánicas que ordenan los órganos constitucionales completando los dictados constitucionales al respecto. Estos órganos serían susceptibles de entrar en confrontación suscitando un conflicto de atribuciones para resolver el cual podría ser necesario acudir a las leyes orgánicas que regulan sus funciones, normas que vendrían a constituirse en normas parámetro de la constitucionalidad de la actuación de dichos órganos. No se estaría hablando aquí de control de constitucionalidad de disposiciones normativas con rango de ley, sino del control de ajuste constitucional de la actuación de los órganos constitucionales, es decir, el Congreso, el Senado, el Gobierno y el Consejo General del Poder Judicial.

La utilización por la jurisprudencia constitucional de un concepto de parámetro que, amparándose en un principio en estos preceptos de la Ley Orgánica del Tribunal Constitucional, va más allá de lo previsto estrictamente en el texto constitucional significa que se da una apertura, que se reconoce el carácter sui generis de la Constitución (STC 4/81) que, al

31 En cualquier caso para profundizar en el análisis de esta cuestión, véase el trabajo ya citado de RAMÓN FERNÁNDEZ, T., Las leyes orgánicas y el bloque de la constitucionalidad: en torno al artículo 28 de la Ley Orgánica del Tribunal Constitucional.

${ }^{32} \mathrm{El}$ artículo 73 ha de interpretarse sistemáticamente acudiendo al art. 59 que dice que el Tribunal Constitucional resolverá los problemas que surjan en torno a las competencias o atribuciones asignadas por la Constitución, los Estatutos de Autonomía o las leyes orgánicas u ordinarias dictadas para delimitar los ámbitos propios del Estado y de las Comunidades Autónomas. 
no ser una «norma cerrada» en todos sus extremos, no puede servir como exclusivo parámetro de validez del resto de las fuentes del ordenamiento jurídico.

Desde sus primeras sentencias, el Tribunal Constitucional ya recurre a la previsión del art. 28.1 LOTC, y acude a disposiciones de rango infraconstitucional como parámetro de control de la validez de otras normas. Así en el año en que inaugura su jurisprudencia, en la STC 36/81, concretamente, se sirve de la previsión del artículo 28.1 LOTC, para considerar que los Estatutos de Autonomía, en este supuesto de hecho el del País Vas$\mathrm{co}^{33}$, forman parte esencial del parámetro que debe utilizar para examinar la constitucionalidad de las normas de cuya impugnación conoce.

No obstante habrá de esperar hasta 1982 para observar la introducción del concepto de bloque de la constitucionalidad en un pronunciamiento del Tribunal, exactamente en el fundamento jurídico 2. ${ }^{\circ}$ de la sentencia 10/82 que se encarga de establecer, sin género de duda, que sólo se podrá interpretar debidamente la normativa aplicable al caso si se fija el bloque de constitucionalidad que ha de servir de base para enjuiciar la ley impugnada, y que este bloque está formado esencialmente por la Constitución y los Estatutos de Autonomía a los que ésta se remite con carácter general para que determinen las competencias autonómicas. En el mismo sentido seguirá pronunciándose después en muchas otras sentenicas a lo largo de los años, sentencias entre las que cabe destacar la 38/83, 137/86, 20/88, 76/88, 181/88, 132/89, 177/90, 149/91, 146/92, 23/93, 25/93, 239/02, 230/03, y 291/05.

A partir de ese momento el conjunto de las normas caracterizado por ser utilizado como parámetro directo de constitucionalidad en la actividad del Tribunal Constitucional empieza a ser denominado por éste como bloque de constitucionalidad, tomando el término de la doctrina jurídica. De hecho el Alto Tribunal afirma expresamente que «la noción de "bloque de la constitucionalidad" hace referencia a un conjunto de disposiciones utilizables como parámetro de la legitimidad constitucional de las leyes» (SSTC 66/85, 29/86 y 175/88). A lo cual añade que la Constitución, y los

33 Además el Tribunal introduce en este momento el concepto de antiestatutariedad, que implica la contradicción entre una ley y un Estatuto de Autonomía, pero en realidad, el propio juzgador se encarga de aclarar que este término queda comprendido en el de inconstitucionalidad en virtud de los artículos 161.1.a) CE y 27, 28.1, y 39 LOTC. Dice literalmente el Tribunal Constitucional en el fundamento jurídico $4 .^{\circ}$ de esta sentencia: «En la medida en que en el caso que examinamos la Comunidad Autónoma del País Vasco ha dictado una Ley sin acudir al trámite de la modificación del estatuto de autonomía, ha vulnerado tanto la Constitución - arts. 147.3 y 152.1 - como el propio Estatuto Vasco - arts. 46 y 47 -, siendo, en consecuencia, dicha Ley inconstitucional y antiestatutaria, calificación esta última que, en realidad, queda comprendida en la anterior con base en lo dispuesto en el art. 161.1 a) de la Constitución y en los arts. 27, 28.1 y 39 de la Ley Orgánica del Tribunal Constitucional». 
preceptos estatutarios y legales interpretados de conformidad con ella que se consideren como parámetro de la legitimidad constitucional de una norma impugnada determinarán, en caso de que esta última los infrinja, su nulidad por vulneración del bloque de constitucionalidad (STC 27/87). Es decir, bloque y parámetro de control son considerados por el Tribunal Constitucional como términos absolutamente sinónimos. De hecho en algunas ocasiones el Tribunal utiliza directamente la expresión «parámetro de la constitucionalidad» para referirse a lo que en otras sentencias denomina como «bloque de constitucionalidad» o, en alguna ocasión como «bloque normativo» (STC 29/82).

\section{La configuración del concepto por la doctrina: en busca del «contenido» del bloque}

En un primer momento y tras el análisis de la primera jurisprudencia constitucional, podría parecer que la asimilación entre la «propuesta» del artículo 28.1 LOTC ${ }^{34}$, y el concepto de bloque, es absoluta. Pero lo cierto es que ese artículo habla de una serie de normas que habrán de funcionar como parámetro, y por tanto que formarán parte del bloque, pero ello no significa que sólo las disposiciones citadas en este precepto puedan configurar por sí mismas la totalidad del conjunto de normas interpuestas.

Si el Tribunal Constitucional se limitara a utilizar la Constitución, los Estatutos de Autonomía y las leyes del art. $150 \mathrm{CE}$ como parámetro de constitucionalidad, lo cierto es que no cabrían demasiados márgenes de duda. Parecería que el Tribunal se limita a considerar parámetro directo de constitucionalidad, junto a la Constitución, al conjunto de normas que atribuyen competencias, es decir a las normas citadas en el art. 28.1 LOTC. El problema surge porque el Tribunal Constitucional va ampliando paulatina y «arbitrariamente» las normas que utiliza como parámetro de constitucionalidad, utilizando en ocasiones también las leyes de bases, ciertas leyes delimitadoras de competencias que no son «atributivas de competencias», y otras disposiciones que nada tienen que ver con el reparto competencial. Y se ampara para realizar esta «ampliación», en un argumento que refleja en sentencias como la 75/85, donde afirma que la configuración de la naturaleza de las normas del bloque deja un espacio abierto a distintas posibilidades

34 En relación con las normas referidas en el art. 73 LOTC el Tribunal Constitucional no se ha pronunciado hasta la fecha asimilándolas al concepto de bloque. En cualquier caso ello no resulta extraño, entre otras cosas por el reducido número de recursos para la resolución de conflictos entre órganos constitucionales del Estado que se han presentado hasta la fecha ante el Tribunal. 
legislativas, lo cual significa simplemente que existe, como en muchos otros aspectos relativos al bloque, una indefinición evidente. Sobre estas cuestiones se volverá inmediatamente. De este modo, se llega a convertir en parámetro cualquier norma cuya cualidad de tal sólo se averigua a posteriori, en la propia sede del Tribunal Constitucional, circunstancia que genera un alto grado de inseguridad jurídica ${ }^{35}$.

Esta convicción ha llevado a la doctrina a empeñarse en procurar una sistematización de las normas integrantes del bloque, porque sólo de este modo tiene sentido la utilización del concepto. Sólo si puede identificarse a priori una configuración del bloque de constitucionalidad será útil para la doctrina, y para los operadores jurídicos acudir a un concepto tal, porque la evocación del mismo permitiría visualizar el conjuto de normas dignas de ser utilizadas como parámetro de constitucionalidad por parte del Tribunal Constitucional.

La sistematización procurada por la doctrina responde a dos grandes líneas teóricas. Una de ellas estima que es la naturaleza de las normas que integran el bloque la cuestión determinante de su adscripción al mismo. La otra, de carácter más utilitarista, estima que es la función que desempeñan estas normas en el seno del ordenamiento lo que determinará su pertenencia al bloque.

\subsection{La definición del bloque constitucional según la naturaleza y posición de sus normas en el ordenamiento jurídico}

Existen autores ${ }^{36}$ que defienden que las normas del bloque poseen condición o naturaleza de normas materialmente constitucionales tal y como sucede con el francés bloc de constitutionnalité. Esta naturaleza permitiría determinar la invalidez de toda norma inferior que las contradiga, ya que las califica como normas estructurales de producción jurídica, condicionantes de la validez de las restantes normas del ordenamiento jurídico en la medida

35 Esto, según DíEz PiCAZo «conduce a la inseguridad jurídica, atenta contra la economía legislativa y procesal y, sobre todo, conlleva al máximo grado de desconstitucionalización al destruir la única barrera efectiva frente al legislador estatal ordinario: que no defina competencias» [DíEz PiCAZo, L.M.: «Ley autonómica y ley estatal. Sobre el significado del principio de competencia en el Estado autonómico». REDC, año 9, núm. 25, enero-abril, 1989, pp. 63 y ss, aquí véase en concreto la p. 72]. Es preciso tener en cuenta que según este autor el bloque en principio es caracterizado como conjunto de normas delimitadoras de competencias, con lo cual para él es atentatorio contra el principio de seguridad jurídica el mero hecho de que la caracterización de una norma como atributiva o delimitadora de competencias sea realizada por el Tribunal Constitucional, y no exista una seguridad previa de tal carácter.

36 Por todos, Orozco Muñoz, M.: El régimen especial de Canarias. Su conformación por el bloque de constitucionalidad, op. cit. 
en que establecen las reglas competenciales y procedimentales para su producción normativa. Según esta concepción, tal posición de las normas del bloque de constitucionalidad permitiría configurarlas como normas jerárquicamente superiores al resto de las del ordenamiento jurídico, rigiendo entre éstas y aquéllas - y para la solución de las antinomias que pudieran surgir-, el principio de jerarquía normativa.

Esta posición parte de la idea de que las normas del bloque son, todas ellas, disposiciones materialmente constitucionales ${ }^{37}$, uniéndose a esta condición, en algunos casos, la de ser también normas formalmente constitucionales, como sucede en el caso de la propia Constitución ${ }^{38}$.

Los autores que defienden esta superioridad jerárquica hallan su justificación en un nutrido número de razones. Entre ellas destacan las que sitúan como argumento central que legitimaría la posición jerárquicamente supraordenada:

a) La «función constitucional» que desempeñan ${ }^{39}$, a la que ya se hará inmediata referencia.

b) La especial resistencia de las mismas a su derogación o modificación por otra norma, aun cuando sea del mismo rango, salvo que se haga de un modo específico constitucionalmente previsto ${ }^{40}$. El paradigma de este argumento es la resistencia de los Estatutos de Autonomía, formalmente aprobados como ley orgánica (art. $81 \mathrm{CE}$ ), a ser modificados por otras leyes orgánicas que no hayan sido aprobadas por el procedimiento específico previsto para la reforma estatutaria en el propio Estatuto y en la Constitución (art 146, 147.3 152.2 CE).

c) La especial relación que vincula a las normas parámetro y al resto. Porque si se ha caracterizado, como es frecuente, las normas del bloque como normas creadoras o atributivas de competencias, éstas se relacionarían con las disposiciones cuya esfera competencial delimita, no por medio del principio de competencia, que parecería

37 Rubio Llorente. F: «El bloque de Constitucionalidad», op. cit., p. 16. En el mismo sentido, Ruiz Huerta CARbonell, A.: Constitución y legislación autonómica: un estudio del bloque de constitucionalidad en el Estado autonómico español. Ibidem. Madrid, 1995, p. 185.

38 Para algún autor, la superioridad jerárquica sobre las fuentes del ordenamiento no integradas en el bloque de constitucionalidad sólo se predicaría de las normas integradas formalmente en la Constitución, mientras que las restantes normas del bloque sólo gozarían de superioridad jerárquica cuando el contenido de las mismas se ajustase a los límites determinados por la Constitución formal. Por todos, OROZCo MuÑOz, M.: «El régimen especial de Canarias. Su conformación por el bloque de constitucionalidad». Op. cit.

39 Gómez Ferrer Morant, R.: «Relaciones entre leyes: competencia, jerarquía y función constitucional». RAP, núm. 113, 1987, pp. 7 y ss.

40 Piniella Sorli, J. S.: Sistema de fuentes y bloque de constitucionalidad: encrucijada de competencias. Bosch, D. L. Barcelona, 1994. 
lo más lógico, sino por el principio de jerarquía, porque «sólo se pueden definir competencias si se posee una fuerza normativa superior $\mathrm{y}$, por consiguiente, si se abarca un espacio material de normación que englobe el de las normas definidas» ${ }^{41}$.

Todos estos argumentos encuentran su contrapunto en las razones que da otro sector doctrinal que defienden que la integración de una norma en el bloque de la constitucionalidad no determina su relación jerárquica con el resto del ordenamiento ${ }^{42}$, y que justifican su posición afirmando que el hecho de que una determinada norma sea considerada parámetro de enjuiciamiento no le concede una posición jerárquica distinta de la que tendría si no gozase de tal condición de parámetro. El razonamiento se completaría con el siguiente argumento: Que la Constitución se vea en la necesidad de ser completada por normas inferiores a sí misma, en la medida en que no decide completamente ni la competencia ni el ámbito y alcance de la regulación de ciertas materias sino que encomienda a otras normas tal empresa ${ }^{43}$, no implica que estas últimas, por el mero hecho de poseer un contenido calificable como materialmente constitucional sean parte de la Constitución, y tampoco que se hallen en una posición de superioridad jerárquica respecto del resto de disposiciones del ordenamiento.

La conclusión que se puede extraer de la propia existencia de dos posiciones doctrinales tan dispares y bien argumentadas como las analizadas es que no está claro que se pueda formular un concepto de bloque de la constitucionalidad en función de una especial naturaleza o jerarquía de las normas que lo integran, porque tal especialidad, que admite argumentos a favor, los admite también en contra.

\subsection{La definición del bloque de constitucionalidad según su función en el ordenamiento}

La doctrina, ante la pobreza de las pautas ofrecidas por el legislador, y la peculiar y poco segura jurisprudencia del Tribunal Constitucional al respecto, ha visto un campo abierto para elaborar un buen número de teorías en torno a cuál sea la función del bloque, y por supuesto en torno a cuáles deban ser las normas que componen dicho bloque con arreglo a la función identificada. Todas estas teorías se agrupan en torno a dos grandes núcleos.

${ }^{41}$ Díez PicAzo, L. M.: «Ley autonómica y ley estatal. Sobre el significado del principio de competencia en el Estado autonómico». Op. cit., p. 68.

${ }^{42}$ Montilla Martos, J. A.: Las leyes orgánicas de transferencia y delegación: configuración constitucional y práctica política. Tecnos, Madrid, 1998, p. 121.

43 Requejo Pagés, J. L.: «Constitución y remisión normativa. Perspectiva estática y dinámica en la identificación de las normas constitucionales». Op. cit., p. 140. 
Uno se refiere al bloque caracterizándolo por su función de delimitación competencial, y otro alude al mismo ciñéndose a su función procesal de parámetro de constitucionalidad.

\subsubsection{LA FUNCIÓN DE DELIMITACIÓN COMPETENCIAL}

Adscritos a esta posición se sitúan los autores ${ }^{44}$ que identifican de manera absoluta el concepto y contenido del bloque, con lo dispuesto en el art. 28.1 LOTC, es decir, con el conjunto de normas que cumplen la función constitucional de delimitar, regular o armonizar las competencias del Estado y las diferentes Comunidades Autónomas ${ }^{45}$.

En esta definición subyace la idea de la Constitución total de Kelsen ${ }^{46}$ que halla su paralelo en nuestro sistema en lo que se ha dado en llamar «la Constitución territorial ${ }^{47}$ » compuesta, de una parte, por disposiciones formalmente constitucionales y de otra por normas post e infraconstitucionales - como los Estatutos de Autonomía y las leyes del art. $150 \mathrm{CE}-$, imprescindibles para conformar un cuadro completo de la forma de Estado, o del modelo de distribución territorial del poder. Y es que «la Constitución no atribuye directamente las materias y competencias a las distintas Comunidades Autónomas, sino que son fundamentalmente los Estatutos de las mismas los que asumen, en méritos del principio dispositivo, las

${ }^{44}$ ApAricio Pérez, M. A.: «Sobre la configuración del modelo territorial del Estado y el bloque de la constitucionalidad», op. cit., pp. 971 y 972; GARCÍA DE ENTERRÍA, E.: Estudios sobre autonomías territoriales. Civitas. Madrid, 1985, p. 299; Gómez FERrer MorANT, R.: «Relaciones entre leyes: competencia, jerarquía y función constitucional», op. cit., p. 23; Piniella Sorli, J. S.: Sistema de fuentes y bloque de constitucionalidad: encrucijada de competencias, op. cit., p. 50; y Rubio LloRENTE, F: «El bloque de Constitucionalidad», op. cit., p. 11.

45 Según Rubio LlORENTE, esta sería una función intrínseca a la norma, que va más allá de su pertenencia al bloque, y que desempeña independientemente de que sea considerada o no parámetro de constitucionalidad. Véase Rubio LloRENTE. F: «El bloque de Constitucionalidad», op. cit., p. 14.

46 Esta Constitución total se refiere a la norma o complejo normativo de rango superior, que distribuye territorialmente el poder - esencial aunque no exclusivamente el poder legislativo-, dividiendo las competencias entre unas instancias centrales y unas instancias locales, que en el caso de la forma de Estado español se identificaría en las Comunidades Autónomas. Esta Constitución total, según Kelsen, «es necesariamente derecho positivo; no puede ser, en modo alguno, un mero supuesto lógico-jurídico», y va a suponer la existencia de «dos círculos normativos ulteriores que son, por relación a aquélla, órdenes parciales delegados: uno, con validez espacial en todo el territorio; y varios, con vigencia circunscrita a determinadas partes del mismo». Kelsen, H.: Teoría General del Estado, 15. ${ }^{a}$ ed. Editorial Nacional, México, 1979, p. 262. Véase, además, la interpretación que hace RuBIo LloRENTE de la «Constitución total» de Kelsen en «El bloque de Constitucionalidad», op. cit., p. 14.

47 Así lo hace CruZ ViLlalón, P.: «Introducción: la Constitución Territorial del Estado», en VV.AA.: El Estatuto de Andalucía (I). Las Competencias. Ariel, Barcelona, 1990, pp. 7 y ss. 
respectivas competencias que se determinan y se delimitan dentro de las previsiones constitucionales ${ }^{48}$. Desde este punto de vista la decisión del constituyente de no cerrar la definición de esta forma de Estado en el texto constitucional, sino en disposiciones externas al mismo supondría una cierta desconstitucionalización de la estructura territorial del Estado ${ }^{49}$.

Los autores que sustentan esta orientación teórica encuentran razones que los asisten, y que exceden su mera capacidad de argumentación, buscando en la jurisprudencia del Tribunal Constitucional que, como se ha visto tiende a vincular el bloque de constitucionalidad al art. 28.1 LOTC, elaborando por tanto una línea jurisprudencial en la que parecería decantarse, precisamente, por la función de atribución competencial de las normas integrantes del bloque.

Desde las ya referidas sentencias del Tribunal Constitucional 36/81 y 10/82, han sido muchos los pronunciamientos que han vinculado la idea de bloque de constitucionalidad exclusivamente a una función de atribución competencial realizada por las normas que lo integran. De hecho el Tribunal Constitucional fijó, en un primer momento, una posición clara, estableciendo que en el bloque de la constitucionalidad, no puede incluirse cualquier ley estatal sino sólo aquellas que establecen una delimitación competencial, en virtud de una previsión constitucional, de los Estatutos de Autonomía o de las leyes marco, de transferencia o de armonización (art. $150 \mathrm{CE}$ ).

Por ejemplo, en la STC 72/83 se decía que una determinada disposición de la que se dudaba su eventual utilización como parámetro de constitucionalidad había de «estar contenida en el bloque de la constitucionalidad, de acuerdo con el art. 28 de la LOTC, es decir, con carácter general, en la Constitución, el Estatuto o en las Leyes determinadoras de las competencias, en el marco de la Constitución». En el mismo sentido se pronuncian un buen número de sentencias posteriores que, además, abordan el concepto de bloque situándolo siempre en paralelo al art. 28.1 LOTC, es decir identificando plenamente dicho precepto con la idea de bloque de la constitucionalidad (SSTC 20/88,181/88, 132/89, 177/90, 149/91, 146/92, 23/93, 25/93, 239/02, 230/03, у 291/05).

Además, en alguna de estas sentencias, se pone de relieve la necesidad de que, para que las leyes infraconstitucionales citadas puedan considerarse integradas en el bloque de la constitucionalidad, y, por tanto, puedan ser utilizadas como parámetro directo de referencia en el control de constitucio-

48 Piniella Sorli, J. S.: «Sistema de fuentes y bloque de constitucionalidad: encrucijada de competencias», op. cit., p. 50.

49 Cruz Villalón, P: «La estructura del Estado o la curiosidad del jurista persa», RFDUC, núm. 4, monográfico, 1982. 
nalidad, a su vez han de superar ellas mismas el test de constitucionalidad. Así se expresa, por ejemplo, en la STC 20/88: «Hay que recordar que la calificación jurídica que las competencias de las Comunidades Autónomas deben merecer no deriva de una lectura aislada de la denominación que tales competencias reciban en los textos estatutarios, sino de una interpretación sistemática de todo el bloque de la constitucionalidad, dentro del cual, como es evidente, la Constitución conserva intacta su fuerza normativa dominante como lex superior de todo el ordenamiento, fuerza normativa que no se agota ni disminuye con la promulgación de los estatutos de autonomía, cuyos preceptos, por más que califiquen como exclusiva la competencia asumida ratione materiae, nada pueden frente a las normas constitucionales que, en su caso, reconozca al Estado títulos competenciales sobre esa misma materia» ${ }^{50}$.

\subsubsection{LA FUNCIÓN PROCESAL DE PARÁMETRO}

La corriente ${ }^{51}$ que defiende la función esencialmente procesal del parámetro de constitucionalidad define el bloque como el conjunto de normas que, con independencia de que posean o no una función intrínseca de delimitación competencial, son utilizadas como parámetro de control por el Tribunal Constitucional que entiende que su infracción por otra norma determina la inconstitucionalidad de esta última, debido a que ocupan una determinada posición en el sistema de fuentes. Dicho de otro modo, las disposiciones normativas integrantes del bloque de constitucionalidad serían todas las normas de distinta naturaleza y rango normativo que, junto a la Constitución formal, sirven a los órganos tutelares del ordenamiento para verificar la constitucionalidad de las restantes normas del mismo ${ }^{52}$, ya que, por sí mismas, determinan la invalidez de las normas de la legislación ordinaria que se les opongan.

50 En este sentido pueden leerse las reflexiones de RoDRIGO BERCOVITZ que considera que el núcleo central del bloque está, efectivamente constituido por la Constitución, los Estatutos de Autonomía y las leyes del art. $150 \mathrm{CE}$, pero afirman que la inclusión en el bloque de estas disposiciones infraconstitucionales no justifica una interpretación de las mismas que exceda de los límites previstos en la Constitución, ya que, tanto los Estatutos como las leyes marco, de transferencia o de armonización están sometidas a la Constitución y «deben ser declarados nulos en lo que manifiestamente entre en contradicción con ella». Véase BERCOVITZ RodríGuez-CANO, R.: «El bloque de la constitucionalidad», en Aranzadi civil, núm.2, 2001, pp. 2173-2175, aquí especialmente p. 2174.

51 Entre ellos destacan las posiciones de OtTO y PARdo, I. DE: Derecho Constitucional. sistema de fuentes. Ariel. Madrid, 1988, pp. 94 y 95; TORNOS MAS, J.: «Ley de bases y legislación de desarrollo. El problema de su articulación por modificación de la ley de bases. La cláusula de prevalencia», $R E D C$, núm. 33, pp. 37 y 38 .

52 ReQUeJo PAGÉs, J. L.: «Constitución y remisión normativa», op. cit., p. 119. 
Para perfilar esta concepción del bloque es preciso acudir al concepto de validez, ya que puede decirse que un precepto se incluye en aquel si su eventual antinomia con otra norma de la legislación ordinaria, se mide en parámetros de validez y no de eficacia normativa. Se trata en este caso, y por oposición a lo que sucede con la función de delimitación competencial, de una función extrínseca a la norma porque surge, independientemente de su contenido material concreto, de su participación necesaria en el proceso constitucional $^{53}$. Cuando se habla del bloque en este sentido no se restringe su contenido a las normas mencionadas en el artículo 28.1 LOTC, pues esta concepción es sustancialmente más amplia que la determinada por dicho precepto legal. Así pues se está ante una consideración procesal del parámetro de constitucionalidad y el propio tribunal reconoce que, en tales supuestos, la noción de bloque de la constitucionalidad, «hace referencia a un conjunto de disposiciones utilizables como parámetro de la legitimidad constitucional de las leyes, pero no a contenidos normativos concretos» (STC 66/85).

La corriente doctrinal que desarrolla esta posición surge como consecuencia del análisis de determinadas sentencias del Tribunal Constitucional en las que el Alto Intérprete propone el uso de un parámetro de control de constitucionalidad más amplio, que va más allá del recurso a las disposiciones relativas a la atribución o desatribución competencial, desplazando los límites que él mismo había colocado en torno al concepto de bloque en sus primeras sentencias y en la mayoría de las sucesivas. Es decir, el Tribunal Constitucional no se ha mantenido siempre fiel a la concepción del bloque meramente atributiva de competencias, y no es difícil encontrar sentencias en las que al estar resolviendo recursos o cuestiones de constitucionalidad y no conflictos de competencias, no se sentirá «obligado» por esta forma de entender el bloque (STC 154/88) y, aunque no lo reconozca expresamente, se colocará del lado de la concepción procesal del bloque de la constitucionalidad.

Un pronunciamiento singular en relación con la redefinición de los contornos del bloque de constitucionalidad es la STC 146/92, en la que al resolverse un recurso de inconstitucionalidad, se afirma textualmente que «a diferencia de lo que ocurre en los conflictos de competencia, las normas constitucionales que operan como canon o criterio de control en el recurso de inconstitucionalidad se extienden a todo el texto constitucional, integren éstas o no lo que se viene llamando el "bloque de la constitucionalidad", es decir, el conjunto normativo del que resulta la distribución competencial entre el Estado y las distintas Comunidades Autónomas». Según esto, la Constitución, pese a ser parámetro de constitucionalidad siempre, no

${ }^{53}$ Rubio Llorente. F: «El bloque de Constitucionalidad», op. cit., p. 15. 
formaría parte en su conjunto del bloque, sino sólo en aquellos capítulos o preceptos directamente relacionados con el reparto territorial del poder (esencialmente el art. 2, el capítulo III del título VIII, las disposiciones adicionales $1 .^{\mathrm{a}}, 3 .^{\mathrm{a}}$, y $4 .^{\mathrm{a}}, \mathrm{y}$ las disposiciones transitorias $1 .^{\mathrm{a}}$ a $7 .^{\mathrm{a}}$ de la Constitución). En realidad esta interpretación no se reitera en la jurisprudencia, pero es una buena muestra de cómo las reflexiones en torno al concepto de bloque de constitucionalidad no son en modo alguno unánimes ni siquiera en el seno del propio Tribunal Constitucional.

Vista esta jurisprudencia del Tribunal y verificado que el mismo acude a disposiciones que no se contienen en las previsiones del art. 28 LOTC para resolver sobre la constitucionalidad de las normas sometidas a su examen, no cabe más que reconocer que el concepto de bloque de constitucionalidad ha de desvincularse del art. 28.1 LOTC, ha de separarse de la noción de Constitución territorial a la que se ha visto vinculado con mayor frecuencia tanto por el Tribunal Constitucional como por la propia doctrina ${ }^{54}$. Si el destinatario único del artículo 28 LOTC, el propio Tribunal Constitucional, ha utilizado un parámetro de control mucho más amplio que el marcado por el precitado artículo, en realidad puede decirse que el contenido del artículo no aporta demasiado más allá de ser una mera fórmula retórica. En esta línea también puede decirse que el Tribunal Constitucional se decanta, lo reconozca o no, por una noción del bloque caracterizada por su función procesal de parámetro.

Así, es la concepción procesal del bloque la que va a permitir un tratamiento más elástico del concepto, que es precisamente lo que le interesa al Tribunal Constitucional, sin perjuicio de que ello le plantee algún inconveniente. Por ejemplo, si se asume que el bloque es el conjunto de normas de las cuales se sirve el Tribunal para llevar a cabo su labor de control de constitucionalidad, no es fácil justificar la exclusión de este bloque de determinado tipo de normas más que afirmando que el Tribunal Constitucional es autónomo y absolutamente competente para determinar dicha exclusión.

Por tanto la posición que aquí se defiende ${ }^{55}$ consiste en abrir el concepto de bloque para que tal denominación comprenda todas las normas-paráme-

54 Según Rubio Llorente, el artículo 28 LOTC no «incluye todas las normas infraconstitucionales que, según el propio Tribunal, se han de tomar en consideración para resolver sobre la constitucionalidad de las leyes sometidas a su conocimiento, ni precisa, salvo por referencia a su función, cuáles son las leyes a las que su apartado primero alude, ni toma en cuenta, en razón de su inserción sistemática, más que un aspecto de esta función». RUBio LLORENTE. F: «El bloque de Constitucionalidad», op. cit., p. 11. En el mismo sentido, es decir reafirmando la desvinculación entre la idea de bloque y el art. 28 se pronuncia RuIz Huerta Carbonell, A.: «Constitución y legislación autonómica: un estudio del bloque de constitucionalidad en el Estado autonómico español», op. cit., p. 154.

${ }_{55}$ En alguna ocasión se ha defendido - Conflicto y cooperación entre la Constitución y el Derecho Internacional, op. cit, pp. 355 y ss - la necesidad de abandonar la denominación 
tro y no sólo las disposiciones normativas atributivas de competencias. En esta línea se colocan otros autores - entre los que destacan Alejandro Ruiz Huerta ${ }^{56}$ y Paloma Requejo ${ }^{57}$ - que, de uno u otro modo, bajo distintos argumentos, abogan a favor de la desvinculación a la que se hace referencia, y ofrecen una nueva noción del bloque de la constitucionalidad.

de bloque de la constitucionalidad y sustituirla por la de parámetro directo de control de constitucionalidad. Pero ha de reconocerse que el uso de esta expresión está tan extendido, que no parece factible que se sustituya su utilización en favor de la adopción de otro tipo de terminología, por lo cual parece más realista y más pragmático admitir que, puesto que es previsible que esta expresión siga utilizándose, será al menos deseable insistir en la necesaria adaptación del contenido y definición del mismo a su verdadera función.

56 Alejandro Ruiz Huerta opina que «hablar de parámetro de constitucionalidad, es hablar de todas y cada una de las normas jurídicas y demás elementos de control, que el Tribunal Constitucional utiliza o puede utilizar en el cumplimiento de su función. Mientras que hablar de bloque de constitucionalidad implica hablar de un determinado conjunto normativo, que cumple una función primordial en el sistema español de control de constitucionalidad, de utilización prioritaria por el Tribunal Constitucional y que está compuesto por un número concreto de normas jurídicas. Es decir, la normativa aplicable al caso». Según esta concepción el contenido del parámetro de constitucionalidad es más amplio que el de bloque estando este último contenido en el primero. Esta concepción implica que las «normas que forman el bloque de constitucionalidad son, cada una de ellas, normas-parámetro, pero, al margen de ellas, existen otros factores de control que también son normas-parámetro. Véase Ruiz Huerta Carbonell, A.: «Constitución y legislación autonómica: un estudio del bloque de constitucionalidad en el Estado autonómico español», op. cit., pp. 145 y 149. Este autor retoma el problema del bloque recientemente en el trabajo «Ante una reforma del bloque de constitucionalidad (BC)», en La reforma de los Estatutos de autonomía, 2003, pp. 147-180.

57 Por su parte Paloma ReQuejo va un poco más allá en la distinción terminológica, estableciendo una innovadora diferencia entre los conceptos de bloque constitucional y bloque de la constitucionalidad. El bloque constitucional, que se correspondería con lo que AlEJANDRo Ruiz HuERTA llama parámetro directo de control, estaría integrado por las normas cuya función es determinar la estructura del sistema constitucional en los casos en que la Constitución no haya formulado definiciones unívocas o no haya completado tales formulaciones en relación con dicha estructura. El bloque de la constitucionalidad, por su parte, se integraría por las normas que se limitan a concretar materialmente aspectos que la Constitución ya ha fijado de modo definitivo con anterioridad, de modo tal que estas normas no innovarían en nada la estructura del sistema jurídico, innovación que sí estaría presente en la función desempeñada por las normas integrantes del bloque constitucional. Dicho de otro modo una fuente determinada se puede considerar como integrante del bloque constitucional cuando aporta algo nuevo a la Constitución, mientras que en el caso de que la fuente se limite a concretar lo que la Constitución regula de modo vago y abstracto, precisando su significado, pero sin aportar nada nuevo, forma parte del bloque de la constitucionalidad. Pero la diferencia fundamental entre ambos conceptos radica en que mientras las normas integrantes del bloque constitucional serán parámetro necesario en todos los procesos de control de constitucionalidad y conflictos de competencias de que deba conocer el Tribunal Constitucional, el bloque de constitucionalidad será apenas parámetro no necesario o parámetro complementario de la propia Constitución. REQUEJo RodRígueZ, P.: «Bloque constitucional y bloque de la constitucionalidad», op. cit., p. 37. 


\section{Las normas que integran un bloque de la constitucionalidad caracterizado por la consideración de su función procesal de parámetro}

Fijada, pues, una posición clara sobre la necesidad de desvincular la noción actual de bloque de la constitucionalidad y la noción de Constitución territorial, la cuestión a determinar acto seguido consiste en la individualización de las disposiciones normativas que caben en esta configuración del bloque de la constitucionalidad.

La Constitución será indudablemente parámetro de control directo, y por tanto integrante del bloque, porque el primer punto de referencia que ha de tomar el Tribunal Constitucional es la norma fundamental de la cual se erige en la condición de supremo intérprete (art. 1.1 LOTC), Y es que esta disposición contiene los parámetros de validez del resto de las normas internas que integran el ordenamiento jurídico en virtud, esencialmente, del principio de supremacía material otorgado a la norma constitucional (arts. 9.1, 95, y 161.1 CE) ${ }^{58}$.

La Constitución se erige en su totalidad en canon de control de constitucionalidad de las normas internas (STC 80/82), tanto en lo que hace a sus contenidos estricta y claramente preceptivos, como en lo que hace a los que, por tener un mayor tinte programático, como los contenidos en los artículos 39 a $52 \mathrm{CE}$, han de ver modulado su valor normativo en los términos del artículo 53.3 CE.

58 En realidad para REQUEJo PAgÉs la Constitución es la única norma que puede ser considerada como parámetro directo de validez del resto de normas. Este autor establece que las normas integrantes de lo que tradicionalmente se conoce como bloque de constitucionalidad, no son parámetro directo de validez, sino causa de invalidez indirecta de la norma sometida a examen de constitucionalidad, puesto que las causas inmediatas de inconstitucionalidad no residen más que en la Constitución. En esta línea de razonamiento REQUEJO afirma que debe hablarse de «antijuridicidad» cuando la norma objeto de examen por parte del Tribunal Constitucional se contraste con las disposiciones infraconstitucionales del bloque de constitucionalidad, y de «inconstitucionalidad», cuando el enjuiciamiento tenga como único parámetro la norma constitucional. Para apoyar su tesis ofrece la siguiente justificación: «Si se califica de inconstitucional a una norma estatal de rango legal que contradice a otra de rango inferior al de la Constitución - un estatuto de autonomía, por ejemplo - aduciendo que con dicha contradicción se está atentando "mediatamente" contra esta última, no hay entonces razón alguna que impida calificar del mismo modo a una norma reglamentaria que contradiga a una ley ordinaria, ya que aquella está vulnerando "indirectamente" la Constitución, al no respetar la ordenación jerárquica que en ella se establece entre las distintas normas. Es evidente que la existencia del Tribunal Constitucional distorsiona en muchos casos la identidad de la Constitución, ya que se suele concebir por tal todo lo que sirva a aquél para el desarrollo de sus funciones»-«Constitución y remisión normativa», op. cit., p. 119-. Así para REQUEJO, que propugna la unidad formal de la Constitución, el bloque lo único que hace es identificar en cada momento el contenido de la norma constitucional, dado que a esta unidad formal de la Constitución se contrapone la pluralidad de sus posibles contenidos y éstos sólo se perfilan en cada una de las formas destinatarias de una remisión constitucional, formas que vienen a integrar el bloque. 
Respecto de las normas internacionales que forman parte del mismo ordenamiento interno, no se puede predicar exactamente lo mismo. En este caso la Constitución no es parámetro total de validez, sino apenas parámetro parcial, ya que buena parte de las condiciones de validez de las normas de origen externo se encuentran en otras normas del mismo origen, quedando limitada la Constitución a establecer las pautas de incorporación de la fuente de derecho internacional al ordenamiento interno - pautas susceptibles de ser consideradas como parámetro de control de constitucionalidad (art. 93 y $94 \mathrm{CE})-{ }^{59}$.

Algún autor ${ }^{60}$ afirma que, si el vicio de inconstitucionalidad alegado en un procedimiento de control de constitucionalidad es un vicio material, el único canon para declarar la inconstitucionalidad de la ley es la Constitución. En el caso de que la invalidez obedezca a vicios en el procedimiento de elaboración, habría que acudir a una concepción procesal de bloque, e incluir en el mismo los reglamentos parlamentarios, mientras que si el vicio es de incompetencia, se acudiría a la concepción competencial del bloque. En cualquier caso, se esté de acuerdo con este planteamiento o se opte por emplear una noción única y general del bloque de la constitucionalidad, válida para todos los recursos y vinculada estrechamente a la idea de «conjunto de normas parámetro», lo que es cierto es que la Constitución integraría cualquiera de las distintas perspectivas del bloque o, dicho de otro modo, sería siempre norma integrante del parámetro de constitucionalidad.

Si bien pudiera deducirse de la lectura de alguna jurisprudencia constitucional (SSTC 29/86 y 146/92) que existe una separación entre el concepto de Constitución y el de bloque, esta disociación, que no genera sino confusión, se debe a la indeterminación del concepto y, sin duda, aporta un buen argumento para apartarse del problemático término de bloque de constitucionalidad, y tender al empleo de un concepto, liberado de la carga connotativa de aquél, como es el de «conjunto de normas parámetro» o «parámetro directo de constitucionalidad».

La cuestión es que la Constitución va a ser siempre norma de referencia, y además va a ser única norma de referencia en el enjuiciamiento de la constitucionalidad del resto las normas que puedan llegar a funcionar como parámetro. Lo dice muy claramente el Tribunal Constitucional en el fundamento jurídico $4 .^{\circ}$ de la sentencia 99/86, donde se afirma que «el

59 En relación con esta posición de la Constitución en relación con las fuentes externas, véase in extenso, mi trabajo, ya citado, Conflicto y cooperación entre la Constitución española y el Derecho Internacional, especialmente las páginas 101 a 118.

60 Por todos, CAAMAÑo, F.: «Los procesos de control de constitucionalidad (I)», en VV.AA.:

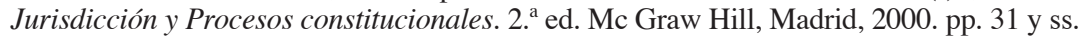


único parámetro para enjuiciar la validez constitucional de una disposición incluida en un estatuto de autonomía es la propia Constitución; esto es, la constitucionalidad de un precepto estatutario sólo puede enjuiciarse sobre la base de su conformidad con la Norma fundamental».

El control de ajuste entre las normas-parámetro con rango de ley y la Constitución no sólo es posible, sino que puede efectuarse siempre que sea necesario, y con ocasión de cualquier procedimiento, dentro de los plazos en ellos fijados ${ }^{61}$. Obviamente la verificación podrá ser favorable o desfavorable, pero en el caso de que la norma controlada sea un Estatuto de Autonomía, debería procurarse la interpretación de la norma conforme a la Constitución cuando ello sea posible, antes que la declaración de inconstitucionalidad $^{62}$, por la carga política indudable que tendría la sanción de nulidad de un precepto estatutario.

El segundo gran grupo de normas-parámetro lo componen las disposiciones normativas que constituyen la Constitución territorial ${ }^{63}$, es decir los Estatutos de Autonomía (SSTC 10/82 y 133/90) ${ }^{64}$ y las leyes del artículo $150 \mathrm{CE}$ (STC 341/2005) ${ }^{65}$. En todas ellas se identifica la misma característica que es la que determina su pertenencia al grupo de normas parámetro: la circunstancia de que son normas que atribuyen, regulan o armonizan las competencias asumibles por las CCAA.

Esta caracterización ha generado un problema teórico con reflejo en la jurisprudencia constitucional y que se resume en la siguiente interrogante: ¿son normas parámetro - normas del bloque de constitucionalidad - las disposiciones no atributivas de competencias pero que aplican los criterios de delimitación fijados en la Constitución, los Estatutos y las leyes del

${ }^{61}$ La opinión de RuBio es disidente en este punto, ya que afirma que las normas integrantes del bloque no son susceptibles de impugnación directa si no es a través del recurso de inconstitucionalidad. RuBIo LlORENTE, F: «El bloque de Constitucionalidad», op. cit., p. 23.

${ }^{62}$ Fernández Farreres, G.: «Artículo 28». En VV.AA.: Comentarios a la Ley Orgánica del Tribunal Constitucional. Coedición del Tribunal Constitucional y Boletín Oficial del Estado. Madrid, 2001, p. 406.

63 Para profundizar sobre el contenido y la forma de todas estas disposiciones, así como sobre su posición en el seno del ordenamiento jurídico español, puede consultarse GómEZ FERNÁNDEZ, I.: «El marco normativo del sistema de organización territorial en España: el sistema de fuentes», en G. Moreira MAuÉs, A. y GómEZ FernÁndeZ, I. (Coord.): Ordenamiento territorial en Brasil y en España, Tirant Lo Blanch, 2006, pp. 93-137.

64 Vide la obra de Aguado Renedo. C.: El estatuto de autonomía y su posición en el ordenamiento jurídico. CEPC. Madrid, 1996, así como el artículo de SÁNCHEZ NAVARRO, A.J.: «Los Estatutos de Autonomía en el sistema español de fuentes del derecho». Sociedad y Utopía. Revista de Ciencias Sociales. Núm. 13, mayo de 1999, pp. 121 y ss.

${ }^{65}$ La Ley Orgánica 9/1992, de 23 de diciembre, de transferencia de competencias a Comunidades Autónomas que accedieron a la autonomía por la vía del artículo 143, es expresamente reconocida como parte integrante del bloque de la constitucionalidad en esta STC $341 / 2005$. 
art. $150 \mathrm{CE}$ ? Entre estas normas se encontrarían, por ejemplo, las leyes de bases, los decretos de traspaso, y otras leyes que delimitan competencias en virtud de la aplicación o el desarrollo de las previsiones constitucionales contempladas en:

- El art. 148.1.2 CE, que formula un reenvío a la Ley 7/85 de 2 de abril, reguladora de Bases del Régimen Local, al establecer que «las alteraciones de los términos municipales comprendidos en su territorio y, en general, las funciones que correspondan a la Administración del Estado sobre las Corporaciones locales y cuya transferencia autorice la legislación sobre Régimen Local».

- Los arts. 148.1.22 y 149.1.29 CE, que llaman a la LO 2/1986, de 23 de marzo, de Fuerzas y Cuerpos de Seguridad del Estado, cuando establecen que las Comunidades Autónomas coordinan a las policías locales dentro del marco establecido por una ley orgánica y en función de lo previsto en sus Estatutos.

- El art. 152.1 CE que obliga a acudir a la Ley Orgánica 6/85 del Poder Judicial, de 1 de julio para que ésta sirva de base al establecimiento estatutario de los supuestos y las formas de participación de las Comunidades Autónomas en la organización de las demarcaciones judiciales del territorio.

- Y el art. 157.3 CE que exige de una ley orgánica - Ley Orgánica 8/1980 de Financiación de las Comunidades Autónomas-, que regule el ejercicio de las competencias financieras de las Comunidades Autónomas. ${ }^{66}$

A este respecto la doctrina no ha llegado a un acuerdo y las posiciones oscilan ${ }^{67}$ entre los defensores de que se integren en el bloque de constitucionalidad exclusivamente las normas que implican delimitación del reparto competencial, es decir atribución o redistribución de competencias ${ }^{68}$,

${ }^{66}$ De entre las normas usadas como parámetro de referencia y vinculadas al Estado autonómico, aunque no se refieran de forma directa al reparto competencial puede dictarse la LOFCA, utilizada como parámetro en las SSTC 183/88 y 48/2004 (esta última también incluye en el bloque a la Ley del Parlamento catalán 10/1982, de 12 de julio, de Finanzas Públicas de Cataluña, complementaria de la LOFCA) y la Ley Orgánica 9/1992, de 23 de diciembre, la competencia exclusiva sobre «fundaciones que desarrollen principalmente sus funciones en la Comunidad Autónoma» fue asumida por las restantes Comunidades Autónomas, denominada como integrante del bloque en la STC 341/2005.

67 Se hace un análisis en profundidad de las distintas posiciones doctrinales al respecto en GómEZ FERNÁNDEZ, I.: «El marco normativo del sistema de organización territorial en España: el sistema de fuentes», op. cit., pp. 132 y ss.

${ }^{68}$ Por todos, Fernández Farreres, G.: «Artículo 28», op. cit, pp. 406 y ss.; Gómez FerRer Morant, R.: «Relaciones entre leyes: competencia, jerarquía y función constitucional», op. cit., p. 29 y 31 y Rubio LlORENTE. F: «El bloque de Constitucionalidad», op. cit., p. 20. 
y los autores que abogan por considerar parámetro de constitucionalidad todas las disposiciones que condicionan el contenido de las normas autonómicas $-\mathrm{y}$, por tanto, también las leyes de bases y el resto de las citadas más arriba- ${ }^{69}$.

Por su parte, la jurisprudencia del Tribunal Constitucional describe una línea principal en la cual reconoce la posibilidad de utilizar las leyes de bases como parámetro interpretativo del bloque de la constitucionalidad, pero no reconoce su capacidad para entrar a formar parte integrante del mismo (SSTC 137/96; 156/95), como tampoco reconoce tal carácter a los decretos de traspaso respecto de los cuales se dice que ni crean, ni alteran el orden de competencias establecidas en la Constitución (SSTC 25/83; $102 / 85,11 / 86,88 / 87,209 / 90$ y 118/98). Extrayendo un principio general de estas sentencias podría decirse que sólo se incluirían en el bloque, como parámetro directo de constitucionalidad, las normas atributivas de competencias, y no aquellas que se caracterizan por suponer el desarrollo de una competencia previamente atribuida en una disposición constitucional, estatutaria o incluida en una ley marco, de transferencia o de armonización. Estas últimas, entre las que destacan las leyes de bases, podrían ser utilizadas como parámetro interpretativo, o como parámetro indirecto de constitucionalidad de otras normas, especialmente normas autonómicas, pero no como parámetro directo (STC 165/95).

No obstante, este principio general quiebra en presencia de leyes como:

- La Ley Orgánica 8/1980, de 22 de septiembre, de Financiación de las Comunidades Autónomas, que es utilizada como parámetro en las SSTC 183/88 y 48/2004 (esta última también incluye en el bloque a la Ley del Parlamento catalán 10/1982, de 12 de julio, de Finanzas Públicas de Cataluña, complementaria de la LOFCA).

- Y la Ley 7/1985, de 2 de abril, de Bases reguladora del Régimen Local, que, a pesar de ser una ley de bases, es reconocida en varias sentencias por el Tribunal Constitucional (SSTC 27/1987, de 27 de febrero, FJ 5, y 109/1998, de 26 de mayo, FFJ 5 y 12.) como integrante del bloque bajo el argumento que se resume de forma clara en la STC 159/2001: «(...) los preceptos estatutarios y legales configuradores de la autonomía local (o sea, aquellos artículos de la LBRL que sean reflejo inequívoco de los principios contenidos en los arts. 137, 140 y $141 \mathrm{CE}$ ) “interpretados conjunta y sistemá-

69 JIMÉNEZ CAMPO: «¿Qué es lo básico?». Legislación compartida en el Estatuto autonómico». REDC. Núm. 27, pp. 39 y ss.; AJA, E.: «El concepto de competencias concurrentes», op. cit., p. 23; TORNOS MAS, J.: «Ley de bases y legislación de desarrollo (...)», op. cit., p. 34. 
ticamente y de conformidad con la Constitución, son los que deben tomarse en consideración como parámetros de la legitimidad constitucional de los preceptos impugnados ..., de tal manera que su infracción por estos últimos determinaría su nulidad por vulneración del bloque de constitucionalidad aplicable a la materia de que se trata" $(. .$.$) .»$

Existe un tercer grupo de normas-parámetro, que nada tienen que ver con el reparto competencial, pero que desarrollan algún contenido constitucional por remisión expresa de la Constitución a una norma ad hoc de naturaleza específica y que, por ello, se encuentran directamente incardinados a la Constitución.

Cabría incluir en este grupo:

a) Las normas a las que la Constitución se remite para regular el procedimiento de producción de otras normas, básicamente los Reglamentos de las Cámaras $^{70}$ - tanto del Congreso como del Senado, como de las Asambleas parlamentarias de las Comunidades Autónomas (ATC 135/2004) -, que son considerados como parámetro para detectar los vicios in procedendo de constitucionalidad de una ley ${ }^{71}$.

El Tribunal utiliza con frecuencia estas disposiciones como parámetro [ATC 12/86; SSTC 5/82, 101/83, 89/84, 108/86, 99/87, 57/89, 23/90 y 38/99], porque son las normas que prolongan y detallan la Constitución en lo que al procedimiento legislativo se refiere, razón por la cual deberían considerarse, cuando menos, parámetro de la validez formal de las leyes. El hecho de que puedan usarse, fundamentalmente, como referente de la constitucionalidad formal de las normas con rango de ley lleva a que algunos pronunciamientos del Tribunal, entre los que destaca la STC 36/90, se refieran a la consideración de los reglamentos de las Cámaras como parámetro, pero aclarando que no es correcto incluir la generalidad de las normas de los reglamentos parlamentarios, (...) en el bloque de la constitucionalidad, sino que sólo las disposiciones reglamentarias relativas al

70 Fernández Farreres, G.: «Artículo 28», op. cit., p. 399.; MARCO MARCO, J.: «El reglamento parlamentario como parámetro de la constitucionalidad formal de las leyes», op. cit, pp. 129 y ss.; PiQueras Bautista, J.A.: «La infracción de los Reglamentos de las Cámaras y la inconstitucionalidad». En VV.AA.: El Tribunal Constitucional. (Volumen III). Dirección General de lo Contencioso del Estado. Instituto de Estudios Fiscales. Madrid, 1981, pp. 2205 y ss.

71 Pulido Quecedo, M.: La ley orgánica del Tribunal Constitucional (Anotada con jurisprudencia). Civitas. Madrid, 1995. p. 165; MARCO MARCO, J.: «El reglamento parlamentario como parámetro de la constitucionalidad formal de las leyes». En El Reglamento parlamentario en el sistema español de fuentes del derecho. Corts Valencianes. Valencia, 2000, pp. 129 y ss. 
procedimiento de elaboración de las normas con rango de ley podrán ser consideradas parámetro del ajuste constitucional de las mismas.

En Francia, cuya práctica puede llegar a servirnos de referencia por haber heredado el concepto de bloque de su doctrina, los Reglamentos Parlamentarios no forman parte del bloque desde la decisión núm. 97 de 27 de julio de 1978, según la cual el Reglamento de la Asamblea Nacional no tiene en sí mismo, valor constitucional ${ }^{72}$. En el caso de que la norma incluida en un reglamento sea la reproducción de la norma constitucional, no se podrá obviar la utilización de esa norma como parámetro, pero por su pertenencia a la Constitución y no por su pertenencia al Reglamento ${ }^{73}$, lo mismo que si la norma cuestionada, y contraria al Reglamento fuese, por contradecir la norma reglamentaria al mismo tiempo, contraria a algún principio fundamental consagrado en la Constitución. En el mismo sentido se pronuncia la Corte Costituzionale italiana en su SCC 9/1959, de 3 de marzo de 1959.

Siguiendo la postura de los países de nuestro entorno, parte de la doctrina española, estima que, efectivamente, los «Reglamentos deben tenerse en cuenta para determinar la inconstitucionalidad formal de las Leyes, pero sólo cuando se estén vulnerando los preceptos reglamentarios que reproduzcan un precepto constitucional» ${ }^{74}$. La cuestión es que, en este caso, en realidad no sería necesario acudir a la norma reglamentaria, porque la aproximación directa al texto constitucional daría la clave de la inconstitucionalidad de la norma recurrida, sin necesidad de complicar más el razonamiento, ni de ampliar el canon de constitucionalidad. Por esta razón parece más adecuado incluir la totalidad de los Reglamentos entre las normas parámetro ${ }^{75}$, y afirmar de los mismos que son «normas susceptibles de ser tenidas en consideración a la hora de determinar la inconstitucionalidad

72 Pardo Falcón, J.: El Consejo Constitucional Francés, op cit., p. 154; LuCHAIRe, F.: Le Conseil Constitutionnel, op. cit., p. 140.

73 LuChaire, F.: Le Conseil Constitutionnel, op. cit., p. 141.

74 Marco Marco, J.: «El reglamento parlamentario como parámetro de la constitucionalidad formal de las leyes», op. cit., p. 134.

75 Algunos autores ofrecen una tercera opción alternativa, según la cual, «con base en el artículo 72 de la Constitución, siempre es posible determinar la inconstitucionalidad de una ley que vulnere un precepto reglamentario, sea cual sea éste, si bien queda(ría) en manos del Tribunal Constitucional, en función de que el defecto de forma sea grave o leve, declarar o denegar la inconstitucionalidad». En este sentido se pronuncian PIQUERAS BAUTISTA, J.A.: «La infracción de los Reglamentos de las Cámaras y la inconstitucionalidad», op. cit., pp. 2205 y ss. y Biglino CAMPOS, P.: «La revocación de la iniciativa autonómica, la naturaleza de la reserva estatutaria y los Reglamentos parlamentarios como parámetro de la constitucionalidad de la ley». REDC. Núm. 14. Madrid, 1985, pp. 276 y ss. Resume sus postulados MARCO MARCO, J.: «El reglamento parlamentario como parámetro de la constitucionalidad formal de las leyes», op. cit., p. 136. 
formal de las leyes, basándo(se), principalmente, en que el procedimiento legislativo está regulado por los Reglamentos parlamentarios en lo no dispuesto por la Constitución» ${ }^{76}$. Y, avanzando un poco más, no sería preciso limitarse a considerar el Reglamento parlamentario como canon de constitucionalidad formal, sino que el propio Tribunal apunta que podrían ser parámetro de la inconstitucionalidad material de las normas objeto de control (STC 38/99, FJ 3. ${ }^{\circ}$ ). Así pues, en esta línea, nuestro Tribunal Constitucional toma en consideración como canon autónomo de validez constitucional la totalidad del Reglamento, pero modula tal apertura del sujeto de control estableciendo que la «inobservancia de los preceptos que regulan el procedimiento legislativo podría viciar de inconstitucionalidad la ley cuando esta inobservancia altere de modo sustancial el proceso de formación de la voluntad en el seno de las Cámaras» (STC 99/87).

b) Junto a los Reglamentos parlamentarios conformarían esta tercera dimensión del bloque cualquier otra norma a la que la Constitución se remita para la regulación de determinadas instituciones u órganos previstos en la misma y que, eventualmente, sean consideradas de preceptivo análisis por el Tribunal Constitucional, convirtiéndose así en normas de referencia o normas parámetro en orden a comprobar el ajuste constitucional de la disposición cuestionada. Como ejemplos de normas que el Tribunal ha empleado como referente con estas características pueden citarse:

- La Ley Orgánica 11/1983, de 25 de agosto, de Reforma Universitaria (vigente hasta el 13 de enero de 2002) que es utilizada por el Tribunal Constitucional en la STC 187/9177.

- Ley Orgánica 1/1990, de 3 de octubre, de Ordenación General del Sistema Educativo, referida como parámetro en la STC 147/92.

76 Marco Marco, J.: Idem. p. 132. Aboga también por la inclusión del Reglamento en el bloque de la constitucionalidad Punset Blanco, R.: «Normas impugnables y motivos impugnatorios en los procesos de control de constitucionalidad de las leyes». REDC, Año 15, Núm. 43, enero-abril 1995, pp. 209 y ss.

77 En este caso el procedimiento en que se dilucida la cuestión es un proceso de amparo constitucional, pero la cuestión que subyace es una duda de constitucionalidad. La sentencia de base recurrida, fue dictada conforme a los artículos 3 y 4 del Acuerdo del Estado y la Santa Sede en materia de enseñanza, y se alegaba la vulneración por parte de la misma, y, por traer causa en ellos, por parte de los preceptos del convenio internacional, del artículo 27.10 CE. En este caso la LRU es usada por el Tribunal Constitucional como parámetro de constitucionalidad, porque dice que el derecho a la autonomía universitaria contenido en el precepto constitucional alegado, es un derecho de configuración legal. Pero esta sentencia además es interesante porque se cuestiona la constitucionalidad de un tratado internacional de forma indirecta. Si se hubiera concedido el amparo, cosa que no sucedió, debería haberse elevado autocuestión de inconstitucionalidad contra los artículos 3 y 4 del Acuerdo. En el $\mathrm{F}^{\mathrm{o}} . \mathrm{J}^{\mathrm{o}} 1 .^{\circ}$ de la sentencia se afirma la posibilidad de interponer un recurso de inconstitucionalidad contra un tratado internacional. 
- La Ley 4/1980, de 10 de enero, del Estatuto de la radio y la televisión, considerada como integrante del bloque, y además calificada como legislación básica en las SSTC 10/82 y 21/88.

- La ley orgánica de libertad religiosa 7/1980, de 5 de julio, que se incluye en el bloque en la sentencia STC 46/2001.

En todo caso, y para evitar una excesiva ampliación de los límites que contienen este tercer grupo de normas-parámetro, el Tribunal Constitucional ha ido limitando las previsiones que podrían entenderse incluidas en este apartado, diciendo, en primer lugar que la legislación ordinaria no puede ser parámetro de validez de la propia legislación ordinaria, puesto que ello haría inoperante la labor del legislador, y produciría una congelación del ordenamiento, porque ninguna ley ordinaria podría ir contra otra ley ordinaria. Por otro lado, tampoco las leyes de desarrollo o regulación de los derechos fundamentales serían parámetro de constitucionalidad, siendo prueba de ello que la LOTC establece que se protegerán los derechos tal y como se recogen constitucionalmente (art. 41.1 LOTC).

Además se ha negado de forma tajante la función de parámetro al Derecho internacional y al Derecho comunitario.

El Tribunal Constitucional ha establecido que la contravención de un tratado internacional por una norma de rango legal, carece de relevancia constitucional, tratándose de una cuestión de mera legalidad (SSTC 49/88, 84/89, 47/90, 120/90, 28/91, 64/91, 214/91, 142/93, 37/94, 76/94 y 77/95), siendo esto así, porque los tratados internacionales carecen de rango constitucional $^{78}$. Parece, por tanto, que la mera oposición entre una ley y un trata-

78 A esta misma conclusión llegan otros tribunales constitucionales europeos, como el Conseil Constitutionnel. En cuanto a los tratados y acuerdos internacionales, a los que el art. 55 de la Constitución francesa concede superioridad jerárquica sobre las leyes, no forman parte del bloc porque el Conseil rechaza controlar la conformidad de las leyes internas con cualquier tipo de norma convencional, tal y como se ha venido estableciendo desde una decisión de principio de 15 de enero de 1975. En esta decisión el Conseil estima que «une loi contraire à un traité ne serait pas pour autant contraire à la Constitution», es decir, en el caso francés parece que se justifica la consideración de un conflicto de este tipo como cuestión de mera legalidad, debido a la superior posición jerárquica en relación con las leyes, que ocupan en el ordenamiento galo las normas convencionales internacionales según la dicción del art. 55 CF. De algún modo el Conseil viene a decir que sólo controla la validez de las leyes, y correlativamente su constitucionalidad, mientras que la relación entre un tratado y una ley es una relación de aplicabilidad, de modo que los tribunales ordinarios son los encargados de fijar esa relación, sobre la consideración de principio de que un tratado será preferentemente aplicado sobre una ley, cuando su campo de aplicación sea el mismo, es decir tengan la misma eficacia territorial, temporal y material, y cuando se cumpla la condición de reciprocidad. Esta posición constitucionalmente reconocida de superioridad jerárquica del tratado permite al juez ordinario aplicar el tratado con preferencia a la ley sin género de dudas, y sin que ello transforme la cuestión en un asunto constitucional. Esta posición del Conseil es discutida por 
do no supone una cuestión de interés para el Tribunal, puesto que se trata de un problema de eficacia jurídica o aplicabilidad, que atañe directamente a los tribunales ordinarios (SSTC 28/91 y 37/94). Esto significa que el hecho de que una norma de rango legal vulnere las disposiciones de un tratado, no hace de la misma una norma inconstitucional, ni de modo directo, ni de forma indirecta, y en todo caso la convertirá en una norma eventualmente inaplicable o ineficaz, por la sencilla razón de que el juez ordinario se verá obligado a aplicar el tratado internacional en consideración al artículo $96^{79}$ de la Constitución que veda la modificación, derogación o suspensión del tratado a través de mecanismos distintos a los previstos en el propio tratado o en las normas del Derecho internacional general, lo cual incluye la derogación del tratado por derogación tácita de una ley sucesiva en el tiempo contraria al mismo.

La conclusión inmediatamente deducible implica que el tratado internacional no sirve como parámetro de constitucionalidad de las normas internas, y, por lo tanto, no forma parte del bloque de la constitucionalidad. No obstante esta conclusión podría ser puesta en cuestión tras el cambio de rumbo de la jurisprudencia constitucional introducido en la Declaración 1/2004, pronunciamiento que admite que los tratados por los que se ceden competencias a una organización internacional, es decir los tratados de Derecho Comunitario Originario, pueden llegar a constituirse en parámetro de referencia de las fuentes internas, en la medida en que el art. $93 \mathrm{CE}$, que justifica la ratificación de dichos tratados, se defina como cláusula de reenvío de ciertos parámetros de validez constitucional a dichas fuentes externas ${ }^{80}$.

El conflicto entre el Derecho Comunitario Derivado ${ }^{81}$ y las disposiciones internas no se resuelve por el Tribunal Constitucional en términos de validez,

autores como LuCHAIRE, que afirma que la posición del Consejo Constitucional, no parece suficientemente fundada y su competencia para apreciar la conformidad de una ley a un tratado debería ser reconocida al menos en lo que se refiere a tratados multilaterales o humanitarios. LUCHAIRE, F.: Le conseil constitutionnel, op. cit., p. 137.

${ }^{79} \mathrm{La}$ legislación de desarrollo del art. $96 \mathrm{CE}$ viene constituida por el art. 1.5 del Código Civil, y el Decreto 801/1972, sobre ordenación de la actividad administrativa en materia de Tratados Internacionales.

${ }^{80}$ Un análisis en profundidad de esta cuestión es realizado por la autora en «La Constitución Española "frente" al Tratado por el que se establece una Constitución para Europa: entre la necesidad y la conveniencia de una reforma constitucional», en Revista española de Derecho Europeo, núm. 14, abril-junio, 2005, pp. 297-327. Incluso antes de este pronunciamiento del Tribunal Constitucional se apuntaba ya la necesidad de abrir el concepto de bloque a este tipo de tratados en el trabajo Conflicto y cooperación entre la Constitución española y el Derecho Internacional, op. cit., pp. 367-416.

81 Sobre esta cuestión véase in extenso GómEZ FERNÁNDEZ, I.: Conflicto y Cooperación entre la Constitución y el Derecho Internacional, op. cit., pp. 367 y ss. Además un buen número de autores se han detenido en el análisis de la relación entre el Derecho Comunitario y el bloque de la constitucionalidad así: MARTí DEL MoRAL, A.J.: «El derecho derivado co- 
sino de aplicabilidad, y, por tanto, de selección del derecho aplicable, función encomendada a los jueces y tribunales ordinarios en la medida en que esta selección carecería de relevancia constitucional. Así pues el Derecho Comunitario derivado tampoco sería parámetro directo del control de constitucionalidad de disposiciones normativas internas y, consecuentemente, no formaría parte del bloque de constitucionalidad (SSTC 128/99, 208/99, 45/01, $38 / 02)^{82}$, si bien ello no impide que pueda ser considerado como parámetro útil para proceder a la interpretación de los contenidos del bloque. Es elocuente, al respecto, acudir al dictado literal de una sentencia reciente del Tribunal Constitucional, la STC 173/2005 en la que dice el Alto Tribunal:

«A este respecto, hemos afirmado reiteradamente que "el Derecho comunitario no es en sí mismo canon o parámetro directo de constitucionalidad en los procesos constitucionales" (...) Consecuentemente, las controversias competenciales han de ser resueltas de acuerdo con los criterios establecidos al respecto en las normas que integran el bloque de constitucionalidad (...). En el bien entendido que (...) no cabe ignorar que la propia interpretación del orden competencial tampoco se produce en el vacío, por lo que prestar atención a la forma en que se ha configurado una determinada institución en el Derecho comunitario "puede ser no sólo útil, sino incluso obligado para aplicar correctamente sobre ella el esquema interno de distribución competencial" (...) e, incluso, para concluir que la controvertida es una cuestión que "cae dentro de la esfera del Derecho comunitario y no en la del reparto interno de competencias" (...)».

munitario y el bloque de la constitucionalidad», en Noticias de la Unión Europea, núm. 86, 1992, pp. 19-30; PALACIO GonZÁlEZ, J.: «Bloque de constitucionalidad y ordenamiento jurídico comunitario», en Gaceta Jurídica de la C.E.E. Serie D; D-7, septiembre 1987, pp. 293-334; PÉREZ TREMPS, P.: «Derecho comunitario y bloque de la constitucionalidad», en PÉrez Calvo, A. (Coord.): Normativa básica en el ordenamiento jurídico español, 1990, MAP, Madrid, pp. 209-213; RIVERo GONZÁLEZ, M.: «Derecho comunitario europeo y bloque de la constitucionalidad», en La constitución española en el ordenamiento comunitario europeo (I): XVI jornadas de estudio, Vol. 1, Ministerio de Justicia e Interior. Secretaría General Técnica. Centro de Publicaciones, Madrid, 1995, pp. 555-570; SAIZ ArnAIZ, A: «El derecho comunitario, ¿parámetro de la constitucionalidad de las leyes internas?: (a propósito de la Secuencia núm. 384 de 1994, de la Corte Costituzionale italiana», en Revista de Instituciones Europeas; 1995, n. 2 (mayo-agosto), pp. 571-591.

82 Esta afirmación, propia del Tribunal Constitucional, es completada por otra referida al hecho de que la adhesión de España a las Comunidades Europeas primero y a la Unión Europea después, no cabe como pretexto para modificar el esquema del reparto de competencias entre Estado y comunidades autónomas. Dicho de otro modo, que la incorporación del Derecho Comunitario al ordenamiento jurídico nacional no debe alterar la Constitución territorial, y por tanto no debe afectar al bloque, si se entiende éste vinculado a esta Constitución. A esta cuestión entre otras se refiere Palacio González, J.: «Bloque de constitucionalidad y ordenamiento jurídico comunitario», en Gaceta Jurídica de la C.E.E. Serie D; D-7, septiembre 1987, pp. 293-334, aquí específicamente p. 325. 


\section{De un bloque de reparto competencial a un bloque con función procesal de parámetro de constitucionalidad}

El análisis de las páginas precedentes conduce a una consideración del bloque como el conjunto de normas de rango infraconstitucional y legal, en ningún caso supralegal, que el Tribunal Constitucional utiliza para llevar a cabo, dentro de su función de interpretación de la Constitución, la específica labor de control de constitucionalidad, razón por la cual estas normas se consideran parámetro de constitucionalidad del resto de las que integran el ordenamiento jurídico, sin que ello suponga una mayor jerarquía sino sencillamente una función adicional.

Las normas que integran el bloque contienen el parámetro de validez preciso para determinar si la disposición sometida a examen de contraste con ellas, se ajusta o no a ese canon de validez, implicando ese ajuste un reconocimiento de la constitucionalidad de tal disposición, y correlativamente, suponiendo el desajuste una declaración de inconstitucionalidad.

En realidad si el Tribunal Constitucional se mantuviese fiel a este concepto procesal de bloque, que es el que se deduce realmente de su actuación, no existirían mayores problemas conceptuales, puesto que en tal definición cabe cualquier norma que el Tribunal decida utilizar como parámetro directo, por entender que contiene criterios de validez no recogidos en la Constitución, y que resultan imprescindibles para determinar el ajuste constitucional de la norma examinada.

Pero el Tribunal Constitucional no asume plenamente esta dimensión del bloque, que, paradójicamente es la que puede resultarle más útil en su labor interpretativa, sino que trata de ir más allá en la precisión de los términos cerrando el diseño del bloque para adaptarse a un difícilmente entendible artículo 28 de la Ley Orgánica del Tribunal Constitucional, que habla de las normas de atribución competencial como parámetro necesario para la actividad de control de constitucionalidad de normas con fuerza de ley.

Es decir, el Tribunal Constitucional, en un número elevadísimo de ocasiones se refiere al bloque de la constitucionalidad sólo cuando habla de normas de atribución competencial, ni siquiera de delimitación o de interpretación del reparto competencial, sino exclusivamente de aquellas normas que pueden considerarse atributivas de competencias. La razón de ello radica en la consideración de que la Constitución, en lo que se refiere al diseño del reparto territorial del poder, no es un texto cerrado, sino que precisa de disposiciones ulteriores que la completen, configurando de forma precisa el diseño del Estado autonómico. Esto indudablemente es cierto. La Constitución, sin los Estatutos de Autonomía, y sin las normas elaboradas en virtud de las previsiones del artículo $150 \mathrm{CE}$, no sirve como único criterio de validez de las normas infraconstitucionales, puesto que 
sólo el conjunto que conforma con estas disposiciones cuyo contenido es la atribución competencial, es capaz de precisar cuales son los órganos legislativos competentes para elaborar una determinada norma, cuál es el procedimiento correcto de elaboración, qué ente territorial tiene la competencia para regular sobre una determinada materia, y a qué principios debe ajustarse tal regulación.

Pero que esto sea así y que la LOTC establezca que la Constitución y las normas atributivas de competencias han de ser utilizadas como parámetro de validez del resto del ordenamiento, no debe significar necesariamente que este conjunto normativo sea el único que recoja criterios de validez, y sea por tanto el único capaz de integrar el bloque de la constitucionalidad.

Si se estimase que el concepto de bloque viene determinado exclusivamente por las normas que configuran el reparto competencial, quizá habría que convenir que existen 17 bloques de constitucionalidad diferentes, uno por cada Comunidad Autónoma, y no parece que este sea el sentido que quepa dar al bloque. Parece mucho más útil definirlo como un conjunto unitario de normas, un conjunto de disposiciones que el Tribunal Constitucional puede utilizar indistintamente para realizar cualquier juicio de constitucionalidad, independientemente del ámbito territorial a que afecte el conflicto. Indudablemente las disposiciones a que alude el artículo 28.1 LOTC van a «formar parte» del bloque de la constitucionalidad pero no van a «ser» el bloque de la constitucionalidad, pese a la interpretación dada incansable y casi constantemente por el Tribunal Constitucional.

El primer problema de configuración del bloque viene pues determinado por el empeño del Tribunal de ceñirlo a una concepción de mera atribución competencial, lo cual resulta, como se ha dicho, poco convincente. Pero el segundo problema se plantea al comprobar cómo, de forma un tanto soterrada, el propio Tribunal amplía el elenco de sus normas parámetro cuando lo considera necesario, estimando parte integrante del mismo cualquier otra norma cuyos dictados colaboren a perfilar el diseño constitucional de una determinada institución. De esta realidad sólo puede deducirse que el Tribunal admite, implícitamente un concepto procesal de bloque, y que en tal concepto procesal han de caber todas las normas que contengan criterios de validez de otras normas. 